\title{
A CFAST Output \\ Comparison Method and \\ its use in Comparing \\ Different CFAST \\ Versions
}

Daniel M. Alvord

Building and Fire Research Laboratory

Gaithersburg, MD 20899

August 1995

U.S. Department of Commerce

Ronald H. Brown, Secretary

Technology Administration

Mary L. Good, Under Secretary for Technology

National Institute of Standards and Technology

Arati Prabhakar, Director

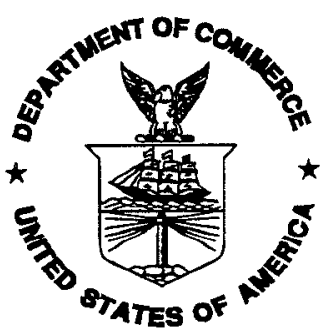




\begin{abstract}
A multiple step method was developed to compare the output of CFAST simulations, produced either by the same version of CFAST, or by different versions of the model. Scenarios to be compared are run with CFAST before the method is used, producing files containing a history of the model results. The first step of the comparison method produces a text file of important output variables from each of these history files, corresponding to significant fire phenomena occurring during the course of each fire simulation. The next step of the method is used to compare two such text files, and store their differences. Finally, the last step summarizes the difference information found in one or more files from the previous step. The comparison method can be used to find differences between CFAST runs, and to track changes in the CFAST model and detect if they perform as anticipated. It has been used to compare three CFAST versions through use of a documented set of test files. This set will change as improvements are made to the model. The method can be used to find the effects whenever any substantial changes are made to CFAST, and is a useful tool for any user of the model. This report describes the comparison method in sufficient detail to serve as a user's guide, provides examples of the method's use, and discusses ways in which it could be improved and generalized.
\end{abstract}

\title{
Keywords
}

building fires; comparison; computer models; computer programs; differences; fire models; fire research; tests

\section{Ordering}

Copies of this document are available from the National Technical Information Services, 5285 Port Royal Road, Springfield, Virginia 22161, at (800) 553-6847 or (703) 487-4650. 


\section{TABLE OF CONTENTS}

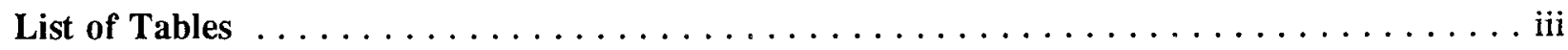

List of Figures $\ldots \ldots \ldots \ldots \ldots \ldots \ldots \ldots \ldots \ldots \ldots \ldots \ldots \ldots \ldots \ldots \ldots \ldots$ iii

1. Introduction $\ldots \ldots \ldots \ldots \ldots \ldots \ldots \ldots \ldots \ldots \ldots \ldots \ldots \ldots \ldots \ldots \ldots$

2. The General Comparison Method $\ldots \ldots \ldots \ldots \ldots \ldots \ldots \ldots \ldots \ldots \ldots \ldots \ldots \ldots \ldots \ldots$

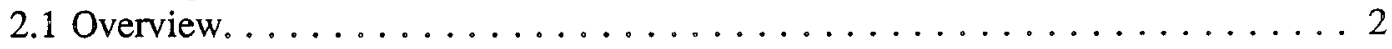

2.2 Performing CFAST Runs to be Compared .................. 4

2.3 REPORTnn - Producing a Text Dump of the Desired

Variables ............................. 4

2.3.1 The Mechanics of the Dump Process ................ 4

2.3.2 Format of the Text Dump File ................... 5

2.4 COMPARE - Comparing Two Text Dump Files ............... 7

2.4.1 The Mechanics of the COMPARE Process. ............ 7

2.4.2 Special Relative Difference Computation and

VARNAMES.DAT . . . . . . . . . . . . . . 8

2.4.3 Format of the Comparison Output File. ............. 9

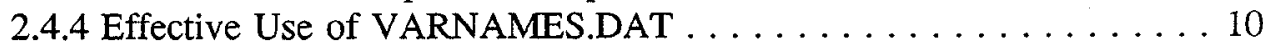

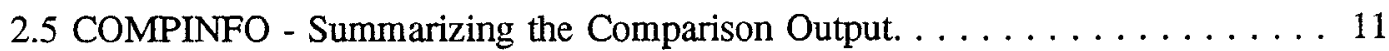

2.5.1 The Mechanics of the COMPINFO Step . . . . . . . . . . . 11

2.5.2 The Five Difference Ranges .................... 13

2.5.3 Format of the Comparison Summary File............... 14

3. The Output Variables Compared for the Different Versions

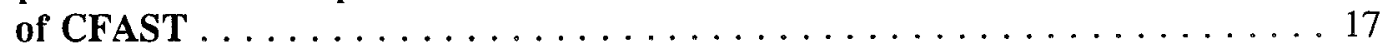

4. Running the Comparison Method Using Two Test Cases .............. 23

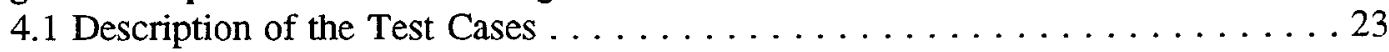

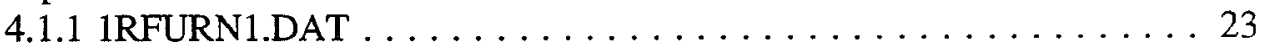

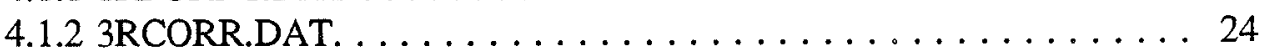

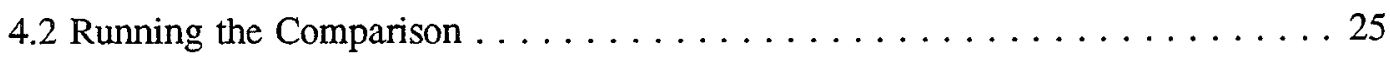

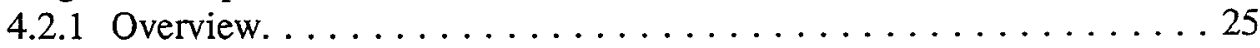

4.2.2 Creating the Binary History Files. $\ldots \ldots \ldots \ldots \ldots \ldots \ldots \ldots \ldots \ldots$

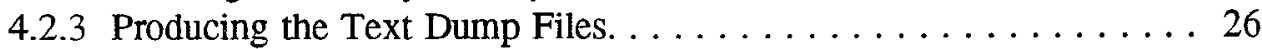

4.2.4 Creating the Comparison Output Files. ................ 27

4.2.5 Producing the Comparison Summary File.............. 28

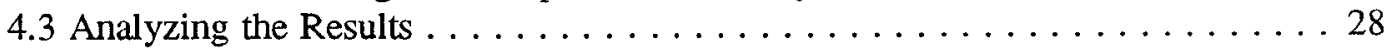

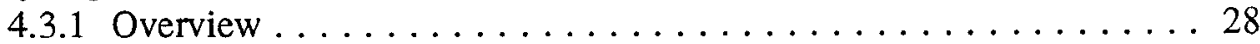

4.3.2 Initial Run of the Comparison Method ............... 30

4.3.3 More Selective Run of the Comparison Method .......... 30

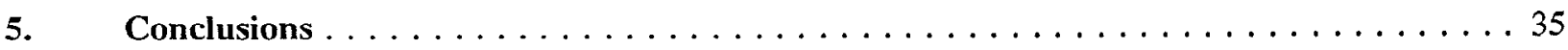

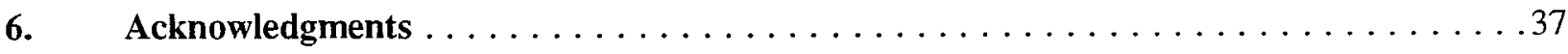




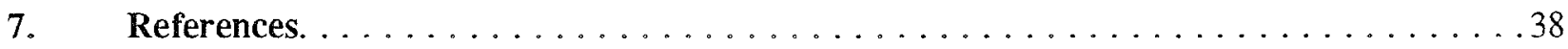

8. Appendix A. One Time Step from the Comparison Output File Produced by the 3RCORR.DAT Sample Case. . . . . . . . . . . . . . 39

9. Appendix B. COMPINFO Output for 1RFURN1.DAT and 3RCORR.DAT runs,

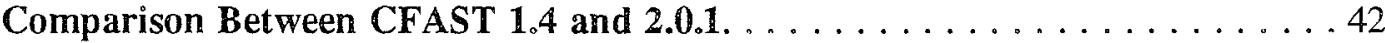




\section{LIST OF TABLES}

Table 1. Variable Names in the Different Comparison Method Versions. . . . . . . 18

Table 2. Short Descriptions of the CFAST Output Variables Used

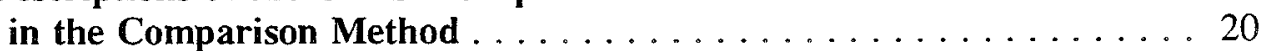

\section{LIST OF FIGURES}

Figure 1. Example Section from a Comparison Summary File $\ldots \ldots \ldots \ldots$

Figure 2. COMPINFO Summary of Differences Between Output from Two

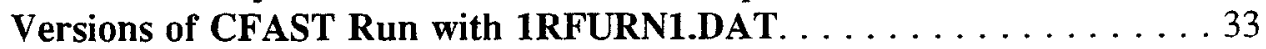

Figure 3. COMPINFO Summary of Differences Between Output from Two Versions of CFAST Run with 3RCORR.DAT . . . . . . . . . . . 34 


\title{
A CFAST Output Comparison Method and its use in Comparing Different CFAST Versions
}

\author{
Daniel M. Alvord \\ Building and Fire Research Laboratory \\ National Institute of Standards and Technology
}

\begin{abstract}
A multiple step method was developed to compare the output of CFAST simulations, produced either by the same version of CFAST, or by different versions of the model. Scenarios to be compared are run with CFAST before the method is used, producing files containing a history of the model results. The first step of the comparison method produces a text file of important output variables from each of these history files, corresponding to significant fire phenomena occurring during the course of each fire simulation. The next step of the method is used to compare two such text files, and store their differences. Finally, the last step summarizes the difference information found in one or more files from the previous step. The comparison method can be used to find differences between CFAST runs, and to track changes in the CFAST model and detect if they perform as anticipated. It has been used to compare three CFAST versions through use of a documented set of test files. This set will change as improvements are made to the model. The method can be used to find the effects whenever any substantial changes are made to CFAST, and is a useful tool for any user of the model. This report describes the comparison method in sufficient detail to serve as a user's guide, provides examples of the method's use, and discusses ways in which it could be improved and generalized.
\end{abstract}

\section{Introduction.}

CFAST [1] is a computer model to predict fire growth and smoke transport in structures with multiple compartments. The implementation consists of a set of programs that describe the building and fire to 
be modeled, predict the fire environment, and produce usable output. Over time, CFAST has evolved to incorporate numerous fire-related phenomena. A method was needed to compare important CFAST output variable values among different versions of CFAST. This would show if improvements in the model perform as planned without side effects, and help find any discrepancies between different versions. It should produce a list of differences between pairs of CFAST simulation output files, and extract useful information from these differences. The comparison method, described in this paper, is such a means.

The method was tested with 107 CFAST input files using CFAST versions 1.4, 1.6.4, and 2.0.1. These 107 cases are a large sample of disparate scenarios that test many different parts of the fire model. The versions of the model were chosen because they are documented and published. The output of CFAST version 1.4 were compared with the corresponding model output produced by version 2.0.1, and those of 1.6.4 were also compared with that version. All of the data files were run with the three CFAST versions, and the comparison method was used to highlight differences among the three versions made evident by these files. This project showed the validity of the comparison method. In the future, the method can be used whenever a change is made to the CFAST model, using the 107 test cases to track changes in model output.

The comparison method consists of several separate steps. First, at least two scenarios are run with CFAST, each producing a history file containing the model output, stored time step by time step. The next step, which is the first step of the actual comparison method, is to produce a text file containing the values of the important variables from each history file. The following step examines pairs of these text files, corresponding to CFAST runs that are to be compared, and places their differences into a comparison output file. Finally, a program is run that summarizes the difference information found in one or more comparison output files created by the previous step.

In this report, section 2 describes the comparison method and its steps in great detail. The important CFAST output variables tracked by the comparison method, as well as their differences between the CFAST versions handled by the method, are given in section 3 . The entire method is demonstrated in section 4. Two sample test scenarios are each executed with CFAST version 2.0.1 and CFAST version 1.4, and their differences compared as a function of the evolution of CFAST. This demonstrates the use of the comparison method and its value in showing changes in CFAST. Future changes anticipated for the comparison method appear in section 5. Finally, two appendices show the results of the comparison method as applied to the two sample test cases.

\section{The General Comparison Method.}

\subsection{Overview.}

The intent of the comparison method is to compare the output of two or more CFAST runs, with the output examination being done in a pairwise fashion. It extracts the important output variable values in each run, and produces information about the differences in these values. This information can be very detailed, showing every difference between chosen pairs of CFAST runs. If desired, the detailed 
information for a group of CFAST runs can be summarized. The comparison method consists of several steps. The terms highlighted in bold, in this part of the report, will be used throughout to describe the output from the appropriate step of the comparison method.

Before the comparison method can be used, a decision must be made about what is to be compared. In the simplest case, two CFAST input data files are each run with (possibly different versions of) CFAST to produce binary history files, which are files containing the simulation output written to disk at a time interval specified in the input file. These files are stored in a compressed format, and require a decompression step whenever their contents are to be examined. In the general case, a great number of CFAST binary history files can be created, as was necessary when comparing CFAST versions over 107 test data files.

As the first step of the comparison method, a program is run to produce a text dump file containing the important variables' values from each binary history file, time step by time step. Two text dump files created in this manner can be compared using another program, producing a comparison output file. The last step is to run a program which analyses the comparison output files that have been produced, and creates lists of variables found to differ in these files, in decreasing order of range of difference. This step summarizes the information contained in the comparison output files, and usually provides sufficient information for analysis.

When using the comparison method to analyze many CFAST runs, use of the last step to summarize the results is necessary to reduce the information generated to understandable levels. It is even recommended when only a few runs are to be compared. Also, the summarized results can show variables whose differences require further investigation. This investigation can be done by means of a careful examination of the more complete information supplied by the previous step of the comparison method.

The steps and programs used for the comparison method, listed by step number, are:

Step 0. (before the comparison method can be used) Select at least two CFAST scenarios to model, and run CFAST to produce a binary history file from each scenario.

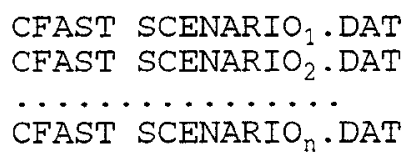

Step 1. Produce a text dump file of the desired variables from the binary history file.

REPORT14 (for CFAST version 1.4 history files)

REPORT16 (for version 1.6 history files)

REPORT20 (for version 2.0.1 history files)

REPORT22 (for history files of CFAST version 2.2, under development)

Step 2. Compare two text dump files and place their differences into a comparison output file. COMPARE (this is independent of the CFAST version)

Step 3. Produce a comparison summary file from a comparison output file or a group of such files. 
These steps will be described in much greater detail in the remaining parts of section 2.

Sufficient detail is provided in this report to enable comparisons to be done. The procedure described in section 4 provides a sample of the method, and section 2 describes the method's steps. The analysis of results is also described, but a thorough analysis requires a certain amount of knowledge about fire phenomena and the availability of CFAST documentation. To minimize confusion when using the comparison method, it is recommended that a logical file naming scheme be used to track an individual CFAST output run throughout the comparison file creation process, as well as to label each step of the method.

\subsection{Performing CFAST Runs to be Compared.}

The comparison method can be used if CFAST binary history files exist corresponding to runs that are to be compared, as long as certain restrictions apply to the version of CFAST chosen to produce the history files. At the moment, history files produced by CFAST versions 1.4, 1.6.4, 2.0.1 (the most recent released version), and 2.2 (the most recent development version) can be analyzed with the method. The restriction to specific versions occurs because of the first comparison step, which must read the binary history file. To accomplish this task, it must use program code from the same CFAST version as the one used to generate the history file. Since most users will compare CFAST results produced by one of the listed CFAST versions, this is not a major constraint. Also, a new first comparison step will be produced whenever necessary to keep pace with the evolution of CFAST.

Most users will probably wish to produce and compare only a few CFAST runs at a time, but there is no restriction within the comparison method itself concerning the number of cases to be compared. There are many possible uses for the method besides CFAST model verification, since it can compare CFAST binary history files produced by the same model version.

\subsection{REPORTnn - Producing a Text Dump of the Desired Variables.}

\subsubsection{The Mechanics of the Dump Process.}

After a binary history file is created with CFAST, the program REPORTnn is used to produce a text dump file containing the desired variables' values for every time step. The naming convention chosen is as follows: REPORTnn is used to process a binary history file from CFAST version n.n. The structure of the history file usually changes when CFAST does, to handle changes in the variables and common blocks within the model. A different version of REPORT is therefore required for each new release of CFAST. It is a straightforward process to prepare a new REPORTnn.

There are currently four different versions of the program REPORTnn, one for CFAST version 1.4, another for 1.6, one for 2.0.1, and the last for version 2.2 under development. 
This step is run by using one of the following four formats:

$\begin{array}{lll}\text { REPORT22 } & \text { HISTORY_FILENAME } & \text { DUMP_FILENAME (given for CFAST 2.2), or } \\ \text { REPORT20 } & \text { HISTORY_FILENAME } & \text { DUMP_FILENAME (given for CFAST 2.0.1), or } \\ \text { REPORT16 } & \text { HISTORY_FILENAME } & \text { DUMP_FILENAME (given for CFAST 1.6.4), or } \\ \text { REPORT14 } & \text { HISTORY_FILENAME } & \text { DUMP_FILENAME (given for CFAST 1.4), }\end{array}$

where HISTORY_FILENAME is a CFAST binary history file, and DUMP_FILENAME is the resultant text dump file. The actual names can be chosen by the user without much restriction, although it is recommended that a logical naming scheme be used.

When REPORTnn is executed, it first reads the CFAST binary history file and sends a recapitulation of the original CFAST input file to the text dump file. It then produces a list of the desired output variables, followed by the maximum subscript values that they attain during the run. Next, it creates a list of active horizontal flow vents (doors, windows, etc.) from the original input file. Finally, it starts its main task. It reads the CFAST binary history file, one time step at a time, and sends the values of the desired output variables to the dump file. An output variable usually has all of its values placed into the text dump file, as determined by the maximum subscript values attained during the simulation. However, some output variables are only defined at active horizontal flow vents, and these are processed specially.

\subsubsection{Format of the Text Dump File.}

The original input to CFAST appears in an expanded form at the beginning of this file, a useful feature for persons familiar with the model. Some items from this output section are extracted by the next step in the comparison method. A small section from the beginning of a representative text dump file will now be shown.

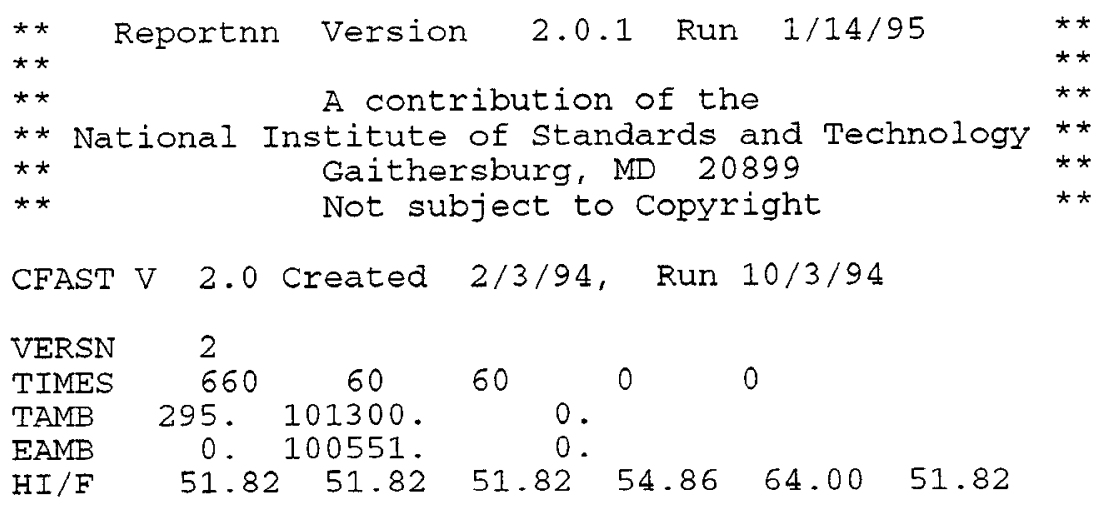

The reader may observe that useful information, such as the current date and the CFAST version number, appears at the beginning of this example section.

Next appears a list of the variables whose values are output, followed by their largest subscript(s) in 
at CFAST simulation time 180 seconds.

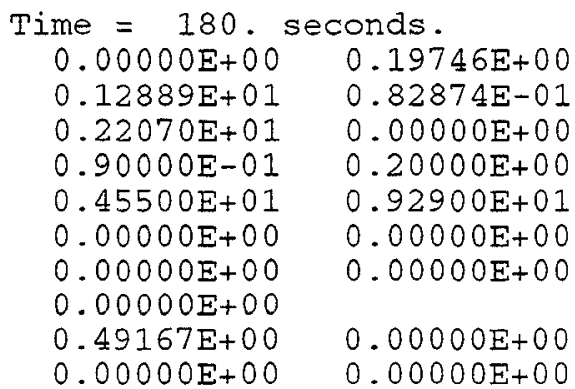

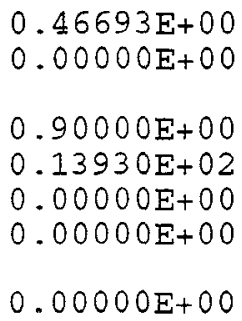

$0.00000 E+00$

$0.13640 \mathrm{E}+01$

$0.45500 \mathrm{E}+01$

$0.00000 \mathrm{E}+00$

$0.00000 E+00$

$0.00000 \mathrm{E}+00$

$0.00000 E+00$

Each time step of values from the binary history file produces a time step of text dump file values. The above example is a section starting at the simulation time 180 seconds, and only shows a small subset of the variable values written at that simulation time. As may be seen, these values do not have any associated identifying information. However, the next step of the comparison method uses the output variable name section to identify the values in each time step.

\subsection{COMPARE - Comparing Two Text Dump Files.}

\subsubsection{The Mechanics of the COMPARE Process}

The program COMPARE finds the differences between the variable values in two text dump files produced by the REPORTnn program. It uses information from each section of a dump file to find the CFAST version used to create the original binary history file, construct variahle names, build the subscripts associated with them, and find where the actual output values of the variables are located.

Initially, it reads information from the first text dump file, up to but not including the output variable values. It examines the variables in the output variable name section (see 2.3.2) of the dump files to find which variables were output, as well as to find the subscript limits. Given a variable name such as ZZHVPR(02,10), COMPARE expands it into the twenty names ZZHVPR(1,1), ZZHVPR(1,2), ZZHVPR(1,3), . . . ., ZZHVPR(1,10), ZZHVPR(2,1), ZZHVPR(2,2), ZZHVPR(2,3) . . . , ZZHVPR $(2,9)$, and ZZHVPR $(2,10)$. In other words, the variable names together with the subscript limits are used to generate the entire list of variables whose output appears at each time step. If the variable name is followed by an asterisk, the name is processed differently. The subscripts used are not generated, but are those found in the section of the text dump file containing the active horizontal flow vents, which appears immediately after the output variable names.

After all names have been generated for the first text dump file, COMPARE performs the same operations for the second dump file. The lists of variables and associated subscripts from both files are then compared, and only variables and subscripts that are common to both files are eligible for comparison. If the two text dump files share some subscripts of an output variable, then the shared portion can be compared. As an example, if the first text dump file contains ZZRELP(06) in the output variable names section, while the second contains ZZRELP(04), then ZZRELP(1) through ZZRELP(4) can be compared. The output from the COMPARE step contains a list of variables, with 
associated subscripts, that appear in one text dump file but not the other.

After a list of common variable names has been produced, the output values within the two dump files are read, one time step at a time, and the output variable values are compared. The comparison output file is augmented as each time step of the dump files is compared, and the program displays on the computer screen all relatively large differences found. If the COMPARE program finds that the simulation time step differs between the two text dump files, a comparison is not performed.

The format for running this step is:

COMPARE DUMP_FILE ${ }_{1}$ DUMP_FILE 2 RESULT_FILE,

where the first two arguments are the names of the text dump files to be compared, and the RESULT_FILE is the name of the comparison output file where the results will be placed.

At present, the variable TOXICT cannot be handled by the comparison method if output produced by CFAST versions before 2.0 is being compared with output produced by version 2.0 or later, since the order of the first two subscripts in TOXICT was changed in version 2.0. A temporary solution for this problem is to put " $\mathrm{N}$ " in the TOXICT line in VARNAMES.DAT (see 2.4.2), and hence avoid comparing values for the variable.

\subsubsection{Special Relative Difference Computation and VARNAMES.DAT.}

The means used to compare a variable value from the first text dump file with the corresponding one from the second file is a relative difference computation. This relative difference between two values $\mathrm{x}$ and $\mathrm{y}$ is defined as follows:

$$
\begin{aligned}
\operatorname{Diff}(x, y) & =\operatorname{Abs}(\operatorname{Max}[x, y]-\operatorname{Min}[x, y]) / \operatorname{Abs}(\operatorname{Min}[x, y]) \\
\text { or, if } \operatorname{Min}[x, y] & =0.0 \\
\operatorname{Diff}(x, y) & =\operatorname{Abs}(\operatorname{Min}[x, y]-\operatorname{Max}[x, y]) / \operatorname{Abs}(\operatorname{Max}[x, y])
\end{aligned}
$$

This definition has one main advantage: the relative difference between $x$ and $y$ is the same whatever the order of the two values $x$ and $y$, which means that the relative difference between two variable values is not dependent upon the order of comparison of the two text dump files. The main disadvantage is that if either $x$ or $y$ is 0 , the relative difference produced will be 1 , whatever the size of the absolute difference $x-y$. No way was found to produce a more "meaningful" value in this situation that would also produce values meshing with the general case.

A file called VARNAMES.DAT is used to define what relative difference criteria are used, as well as to limit the CFAST output variables that will be selected for comparison. VARNAMES.DAT contains a list of all important output variables, with each name followed by a value specifying the maximum permissible difference for that variable, where the difference is as defined above, and a " $\mathrm{Y}$ " or " $\mathrm{N}$ " to show if that variable is to be examined. A sample section from VARNAMES.DAT will now be given. 


$\begin{array}{lll}\text { HVP } & 0.001 & Y \\ \text { MASS } & 0.001 & Y \\ \text { ONTARGET } & 0.001 & Y \\ \text { OPLUME } & 0.001 & Y \\ \text { PPMDV } & 0.001 & Y \\ \text { QC } & 0.001 & Y \\ \text { QF } & 0.001 & Y \\ \text { QR } & 0.001 & Y \\ \text { QRADRL } & 0.001 & Y \\ \text { ROHB } & 0.001 & Y \\ \text { SA } & 0.001 & Y \\ \text { SAU } & 0.001 & Y \\ \text { SS } & 0.001 & Y \\ \text { TBR } & 0.001 & Y\end{array}$

If the file is present, an output variable is only compared if it is common to both text files and is marked " $\mathrm{Y}$ " in this file. If the variable is selected for comparison, the following criterion is used; when pairs of the variables' values are compared, pairs that have a relative difference greater than the maximum permissible difference selected for that variable in VARNAMES.DAT will appear in the comparison output file. If this file is absent, any differences of any size between all variables common to both files are noted in the comparison file.

In the sample section from VARNAMES.DAT, it may be noted that the criteria used for maximum permissible relative difference is set at 0.001 for each variable. This value was deemed small enough to show any significant difference between values. This is the value that should be chosen when the full comparison method is used, including the last step producing a summary, since it is the lower limit defining a difference in the last category, difference range 5 (see 2.5.2). If the user wishes to examine the comparison output file generated by COMPARE, and is not interested in the summary step, the relative difference criteria in VARNAMES.DAT can be increased to reduce the amount of information generated. More information on the flexibility afforded by means of this file is given in section 2.4.4.

\subsubsection{Format of the Comparison Output File.}

The beginning of a comparison output file contains the names of the two text dump files being compared, and the CFAST versions used to generate the initial binary history files. An example is:

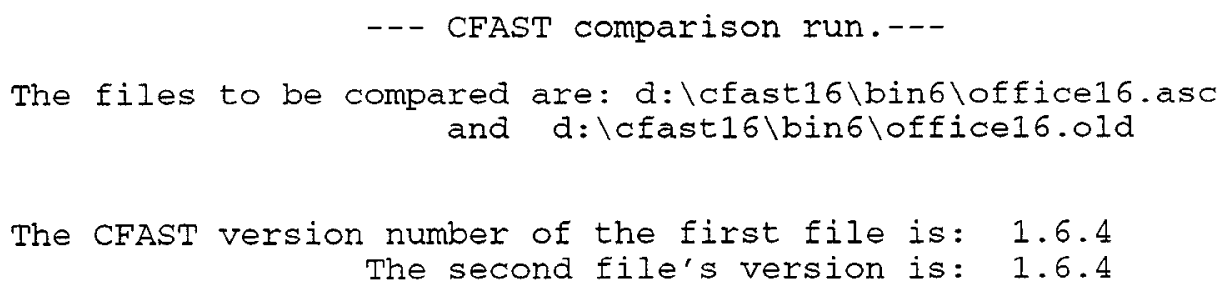

The next section lists the CFAST output variables contained in the first text dump file, but not in the second one. Immediately after this section appears a corresponding one for CFAST output variables contained in the second text dump file, but not in the first. These two sections show which output variables cannot be compared, subdivided by subscript. Some output from one of these sections will now be presented. 
VARIABLE NAMES (INCLUDING SUBSCRIPTS) IN

FILE 2 WHICH HAVE NO CORRESPONDING MATCH IN FILE 1.

$\begin{array}{lll}\text { EME } & 1 \\ \text { EME } & 2 & \\ \text { EMP } & 1 & \\ \text { EMS } & 1 & \\ \text { OPLUME } & 1 & 1 \\ \text { OPLUME } & 1 & 2 \\ \text { OPLUME } & 1 & 3 \\ \text { OPLUME } & 1 & 4 \\ \text { OPLUME } & 1 & 5\end{array}$

The actual comparison information appears after the sections listing any non - comparable output variables. It is arranged by simulation time step, starting at time 0 seconds. A short sample section of output from this step of the comparison method is:

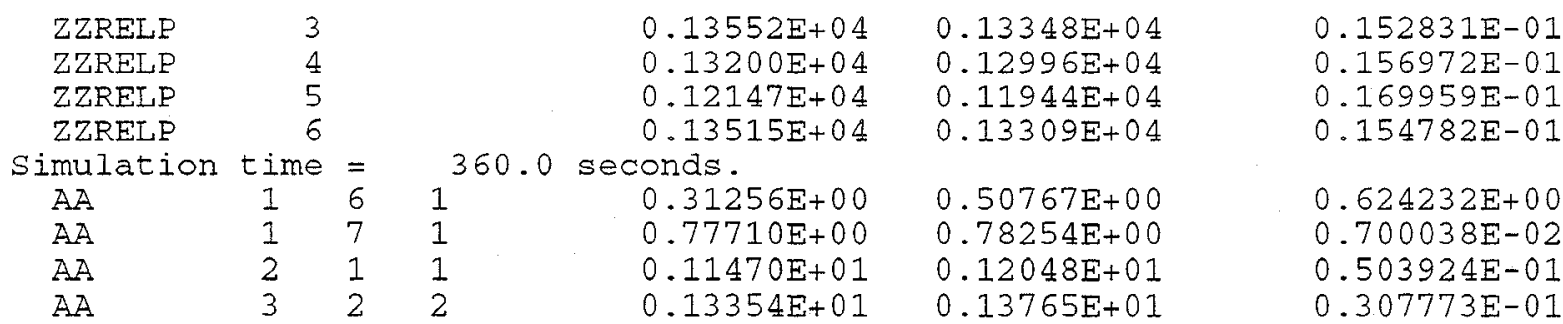

The first item in a line is a CFAST variable name, followed by 0 - 3 subscript(s) uniquely identifying the current values. The variable's value in the first text dump file is next, followed by the value in the second dump file. The last item in a line is the relative difference, computed as defined earlier in section 2.4.2. In the above sample output, the values of ZZRELP(3) through ZZRELP(6) in both files are shown, followed in each case by the computed differences. Four values from the output variable AA also appear. Whenever the values from a new simulation time step are being examined, a new header appears such as the one above showing 360 seconds.

If a user of the comparison method wishes to examine output from this step, some information about these variables appears in Table 2. However, the information needed to find the phenomena being shown by a particular set of subscripts is beyond the scope of this report. The reader should find the information in reference 1 .

\subsubsection{Effective Use of VARNAMES.DAT}

The file VARNAMES.DAT and its relation to the difference calculation used in the comparison method were discussed in section 2.4.2. However, the full capabilities afforded by careful changes to this file were not discussed. These capabilities apply only if the modeler wishes to change the default way in which the comparison output file is produced, and does not wish to use the resulting file as input to the last step in the comparison method. Before any changes to VARNAMES.DAT are 
performed, it is highly recommended that an unmodified copy of the file be preserved.

The comparison output file can easily be more than one megabyte in size when two greatly differing text dump files are being compared, and the relative difference criteria are set at 0.001 , which is the default value. It was determined that increasing the default criteria in VARNAMES.DAT from 0.001 to a much larger value such as 5.000 will filter out all but the most dramatic differences between the dump files, greatly reducing the size of the comparison output file and greatly increasing its understandability. This value may be considered too large for some readers, since it roughly corresponds to a difference of a factor of 5 . Reducing it to a value slightly greater than 1.0 is still quite effective. However, if a value less than 1.0 is chosen, all compared pairs of values where either the first or the second is equal to 0.0 will appear in the output file, since the computed relative difference is 1.0 in this case. There are often many such pairs of values. Another approach is to increase the default number from 0.001 to 0.1 for each output variable, since this usually moderately reduces the comparison output information that is generated and does not greatly compromise the capability to find significant differences. The decision on the precise type of filtering number to use is left to the reader.

Another means to reduce the size of the comparison output file is to choose only the most desired output variables. This is performed by changing all the values in VARNAMES.DAT indicating if a variable is to be examined from $\mathrm{Y}$ to $\mathrm{N}$, except for the desired variables. Next, the COMPARE step is rerun with the new VARNAMES.DAT. The comparison output file will only contain information for the specified variables.

The reader may even increase the relative difference criteria for variables in which there is less interest, change $\mathrm{Y}$ to $\mathrm{N}$ for variables not considered of interest, and not change anything for the remaining variables. This shows the true flexibility the use of VARNAMES.DAT permits.

\subsection{COMPINFO - Summarizing the Comparison Output.}

\subsubsection{The Mechanics of the COMPINFO Step.}

The step of the comparison method that compares two text dump files can produce a great deal of information. In certain cases the comparison output file has been more than 2.5 megabytes in size. COMPINFO will examine comparison output files, summarize the information contained within them, and place the results into a comparison summary file. In many cases, this summary will provide sufficient information for the purposes of the user.

The program COMPINFO requires that a file be created containing the names of all comparison output files to be processed. This file will be referred to as a script file. COMPINFO will examine each comparison output file one line at a time, and use the variable names and relative differences found on the lines to categorize the output variables into five difference ranges (defined in 2.5.2). These ranges vary from range 1 , which consists of output variables with pairs of output values having major differences, to range 5, where all differences are inconsequential. COMPINFO will produce a section in the comparison summary file corresponding to each comparison output file, with much more 
succinct information than the original file. After all comparison output files have been examined, COMPINFO will create a general summary section containing a cross reference of output variables and comparison output file names, grouped into five sections corresponding to the five difference ranges.

COMPINFO can display all relevant information from the comparison file(s) in cases where there are major differences (range 1 differences). A major difference is defined to occur when the relative difference (see 2.4.2) between two variable values is greater than 100 , or one of the variable values is 0.0 (generating a relative difference of 1.00 ) and the absolute value of $x-y$ is greater than 5000 . The program currently only summarizes information for other, less significant, difference ranges.

The format for running this step is:

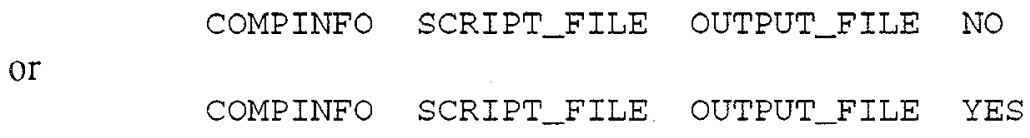

where the SCRIPT_FILE contains the names of the comparison files, one per line, the OUTPUT_FILE will contain the comparison summary from COMPINFO, and the NO or YES shows if a summary of the major differences is desired. If NO is specified, a complete listing of all information for the major differences is given. If YES is chosen, a summary of the major differences will appear. A short example listing with NO selected is:

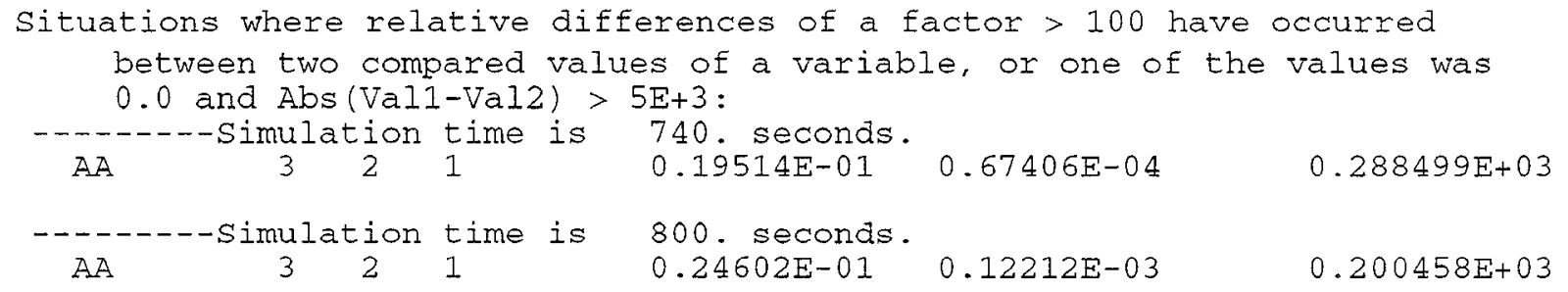

The same example with YES selected is:

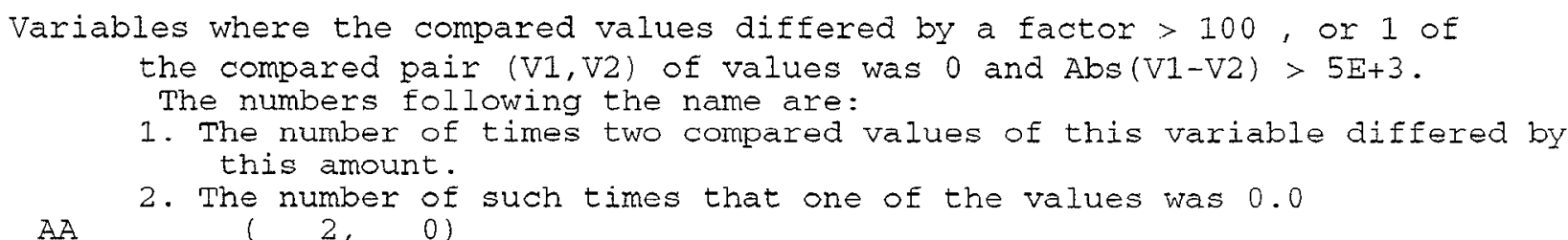

When no summary was selected, it may be seen that all information is given about the two major differences in the variable AA. With the summary selected, the output merely indicates that two major differences occurred.

If each value of a compared pair has "sufficiently small" absolute value, the pair is ignored, since the values are considered insignificant regardless of the output variables being compared. The criteria used to define such cases is: 


$$
\operatorname{Max}[\operatorname{Abs}(\mathrm{x}), \operatorname{Abs}(\mathrm{y})]<10^{-3} \text { and } \operatorname{Min}[\operatorname{Abs}(\mathrm{x}), \operatorname{Abs}(\mathrm{y})]<10^{-4}
$$

The considerations behind this choice were twofold in nature. First, before this criterion was added, many of the differences produced by the COMPARE step and then summarized by the COMPINFO step were being generated by "small" pairs of values, both of which were of small absolute value. The manner in which the difference is computed can generate large values even when both values being compared are small. A decision was made, taking into account the wide range of values that the different CFAST output variables can attain, to choose a means of filtering out these "small" pairs. Secondly, there is some basic uncertainty in CFAST and any fire model due to many things such as incompletely understood physics and necessary numerical simplifications. This uncertainty is probably large enough to permit the removal of very small pairs of values from the comparison method, since it is greater than these small values. The chosen criteria may easily be modified if better information becomes available, since it only occurs in the COMPINFO step.

\subsubsection{The Five Difference Ranges.}

There are five difference ranges used to categorize the results from each comparison output file and to subdivide the general summary results at the end of the comparison summary file. Understanding the definitions of these ranges, and how they are implemented, is important in fully understanding the results produced by COMPINFO.

When examining a comparison output file, the computed difference (see 2.4.2) on each line is used by COMPINFO to subdivide the output variables within that file into 5 difference ranges, arranged in decreasing order of relative difference. These five ranges are defined as follows:

Range 1. Pairs of variable values with the greatest differences. When comparing two CFAST runs, a compared pair of output variable values falls into this category if

A. The compared pair of values $(x, y)$ has a computed difference greater than or equal to 100 ,

or

B. One of the two compared values $(x, y)$ is 0.0 and the absolute value of $(x-y)$ is greater than 5000.0

Range 2. Variable pairs having a computed difference greater than or equal to 5.0 but less than 100 .

Range 3. Variable pairs having a computed difference greater than or equal to 0.5 but less than 5.0 (this includes pairs one of which is 0 , since the computed difference would be $1.0)$.

Range 4. Variable pairs having a computed difference greater than or equal to 0.01 but less than 0.5 .

Range 5. Pairs of variable values with the least significant differences. The pair has a computed difference greater than or equal to 0.001 but less than 0.01 .

A compared CFAST output variable is considered to lie in the difference range of its worst compared 
pair of values. If a variable falls into one difference range, the variable is not considered to lie in ranges with higher numbers for the same comparison output file. For example, assume that during a comparison it is determined that the variable MASS has a worst compared pair that differs by 12.0 , where the difference is computed as in section 2.4.2. MASS is then defined to be in range 2, no matter how many compared pairs of its values have lesser differences falling into those defining range 3,4 , etc. The worst difference is considered the most significant one.

The output of COMPINFO shows the variables arranged into the above difference ranges for each comparison output file processed. For each range listing, the variable name is given followed by the number of compared pairs that have a computed relative difference in the appropriate range. This value shows if only one compared pair fell into the range, or if 1000 pairs did, and therefore helps to provide more information than does the difference range alone.

There are additional considerations for two of the difference ranges. For range 1, the differences with the greatest magnitude, the user has the option (already mentioned in section 2.5.1) of displaying all of the information about each pair that generates candidacy for the range, including the variable name, the subscripts, the values, and the time step. If this option is not specified, summary information identical to that for other ranges will be generated for range 1. Also, when the summary format has been chosen for range 1 , and for range 3 in all situations, there are two numbers following the variable name instead of one. The first is the number of compared pairs with differences in the appropriate range, and the second is the number of such situations where one of the pair of compared values is 0 .

\subsubsection{Format of the Comparison Summary File.}

For each comparison output file processed by COMPINFO, a summary section is generated within the comparison summary file. A complete example section is shown in Figure 1. There is a good deal of internal documentation placed into the output by COMPINFO. As may be seen, the section was generated from a comparison output file called 1R20114.CMP, which in tum was produced from the two text dump files 1RFUR201.ASC and 1RFUR14.ASC. These two dump files contain output from CFAST version 2.0.1 and CFAST version 1.4.0, respectively. This information helps trace the previous steps of the comparison method, and is helpful in documenting the results.

The remaining information in the figure shows which output variables were in each of the five difference ranges. When this summary section was produced, a summary of major differences was selected, and hence the first range has the same structure as the remaining four.

Within each range listing appears a listing of CFAST output variables whose worst relative difference was in the range. The section in figure 1 for range 1 is:

\begin{tabular}{|c|c|c|c|c|}
\hline$A A$ & & $0)$ & AS & 1 . \\
\hline MASS & ( 516, & $0)$ & PPMDV & ( 109, \\
\hline SAU & 3 , & 3) & ZZGSPEC & $(304$, \\
\hline ZZRELP & 200, & 0) & & \\
\hline
\end{tabular}

For the output variable AS, only one compared pair of values differed by an amount lying within range 1. However, there were 516 pairs of values for the variable MASS with major (range 1) differences. The reader can deduce that MASS differed more significantly than AS between the two original CFAST runs. The second number in parentheses after the variable names is the number of 
times that one of the compared values was 0 . For SAU, this situation occurred all three times the relative differences were in range 1.

A summary section within the file generated by COMPINFO can be used as a starting point to acquire additional information. As an example, it may be observed in Figure 1 that the output variable ZZMASS is in difference range 2 . If a user of the comparison method were interested in the precise situations causing this particular output variable to be in range 2, the comparison output file from which the summary section was produced could be examined carefully. To reduce the effort involved, all variables except for ZZMASS could be removed from the comparison method by changing VARNAMES.DAT (see 2.4.4) and recreating the comparison output file. The greatest differences in this output variable between the compared runs could then be easily found.

As each comparison output file listed in the script file (see 2.5.1) is processed, a new summary section of the above format is produced within the comparison summary file. At the end of the summary file appears a general summary section, consisting of a listing of CFAST variables and comparison output files, arranged into the five difference ranges. The ranges appear in decreasing order of magnitude of noted difference.

Range 1 summary information appears first, range 2 follows, . . . and range 5 data is last. In each section appear all of the CFAST output variables for which at least one compared pair of values in a comparison output file differed by this range. Following the variable name are two numbers, with the first being the number of test data files that generated this situation, and more importantly, the total number of times that a compared pair of the variable's values differed by this amount over all test data files analyzed by COMPINFO. Appearing to the right of these numbers are the names of the comparison output files in which compared differences occurred in the output variable of a severity corresponding to that range, with the parts of the file names following the period removed. If all compared pairs of values of the variable that generated the appropriate difference range had one member with a value of 0 , an asterisk appears in front of the relevant comparison output file name. This variable listing appears even if "NO" is selected when running COMPINFO, and is not related to the "NO Summary" feature for major differences. A few lines taken from the range 2 section of a general summary section are:

Final Summary for range
Relative difference is at most $>=5.0$ but $<100.0$
AA
IRWALI1

In this example the variable AA fell into difference range 2 in 17 comparison output files, a total of 79 times. The names of the comparison output files in which AA was in range 2 are also shown. A complete general summary section appears at the end of Appendix B. 
The comparison file being examined is 1 r20114.cmp

The files to be compared are: . \comparir \1rfur201.asc

and . \comparir \Irfur14.asc

The CFAST version number of the first file is: 2.0 .1

The second file's version is: 1.4 .0

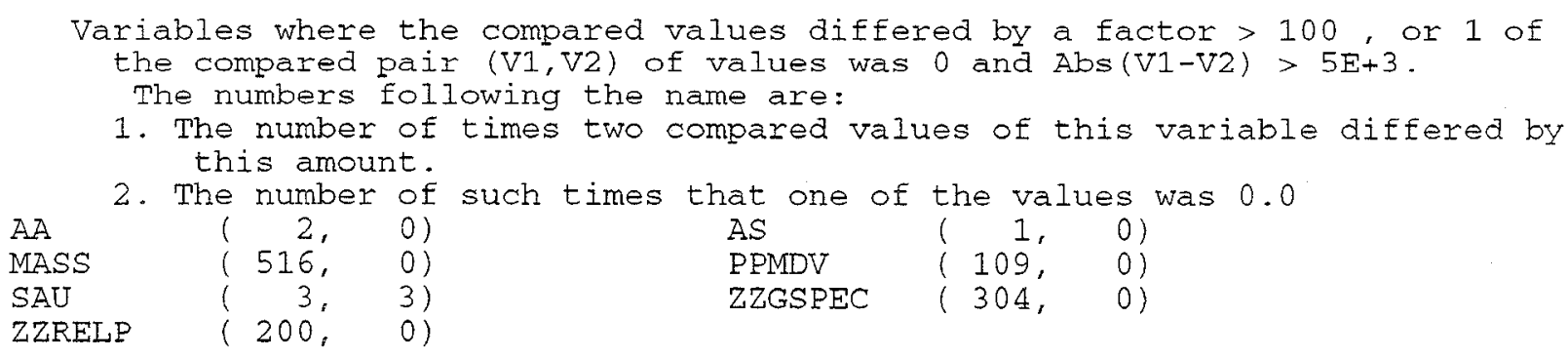

Variables with compared relative difference at most $>=5.0$ but $<100.0$. The number following the name is the number of times the variable values differed by this amount:

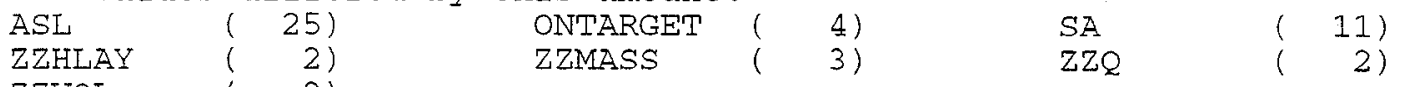

ZZVOL

2)

Variables whose relative difference is at most $>=0.5$ but $<5.0$ :

(If either value is 0.0 the relative difference will be 1 , except in

the following situation: if both values have "very small" absolute

values, the relative difference is set to 0.)

The numbers following the name are:

1. The number of times two compared values of this variable differed by this amount.

2. The number of such times that one of the values was 0.0

$\begin{array}{llll}\text { APS } & (1,1) & \text { QRADRL } & (201,201) \\ \text { TWE } & (804,804) & \text { TWJ } & (16,1) \\ \text { ZZTEMP } & (12,10) & & \end{array}$

Variables with compared relative difference at most $>=0.01$ but $<0.5$ :

- NONE --

Variables with compared relative difference at most $>=0.001$ but $<0.01$ :

-- NONE --

Figure 1. Example Section from a Comparison Summary File 
The general summary at the end of the COMPINFO output file is especially useful when a large number of comparison output files are being analyzed, as was the case in the CFAST version comparison using 107 test data files. The correlation between output variables and comparison output files within different levels of relative difference provides a grand overview of the changes.

\section{The Output Variables Compared for the Different Versions of CFAST.}

During the evolution of the CFAST fire model, some output variables have been added, deleted, and renamed. One trend over the past several versions of CFAST has been the replacement of some output variables by equivalent variables beginning with the letters $Z Z$, an example being the replacement of MASS by the variable ZZGSPEC.

Table 1 shows the CFAST output variables tracked in the comparison method for CFAST versions 2.0.1, 1.6.4, and 1.4. The variable lists for CFAST versions 1.4 and 1.6 .4 are very similar, except for variables ZZCSPEC, ZZHVM, ZZHVPR, and ZZWTEMP, which were not in version 1.4. The lists of variables for version 1.6.4 and 2.0.1 have greater differences. When comparing two different outputs from different versions of CFAST, only variables present in both versions can be compared. There is no such problem if two outputs produced by the same version are being examined.

A short description of each variable in terms of the phenomena it represents, as well as its numeric type, is given in Table 2. The number of subscripts for each variable can be seen by counting the values in parentheses following the variable name. Not all values for the variables TWJ and ZZWTEMP are output for the comparison method. For TWJ, only surface temperature was considered of interest $(\mathrm{TWJ}(1, * *))$, while only inside wall temperatures were deemed important for ZZWTEMP (ZZWTEMP $(*, *, 1))$. There are also variables whose values are only updated at subscripts corresponding to active horizontal flow vents, and for such variables only these subscripts are used by the method. Further information about the output variables and the meaning of their subscripts may be found in reference [1]. 
Table 1. Variable Names in the Different Comparison Method Versions.

\begin{tabular}{|c|c|c|c|}
\hline Variable Name & CFAST 2.0.1 & $\overline{\text { CFAST 1.6.4 }}$ & CFAST 1.4 \\
\hline $\begin{array}{l}\text { AA } \\
\text { AFIRED } \\
\text { APS }\end{array}$ & $\begin{array}{l}* \\
* \\
*\end{array}$ & $\begin{array}{l}* \\
* \\
*\end{array}$ & $\begin{array}{l}* \\
* \\
*\end{array}$ \\
\hline $\begin{array}{l}\text { AS } \\
\text { ASL } \\
\text { BFLO }\end{array}$ & $\begin{array}{l}* \\
* \\
*\end{array}$ & $\begin{array}{l}* \\
* \\
*\end{array}$ & $\begin{array}{l} \\
* \\
*\end{array}$ \\
\hline $\begin{array}{l}\mathrm{BW} \\
\mathrm{CE} \\
\mathrm{EME}\end{array}$ & $\begin{array}{l}* \\
*\end{array}$ & $\begin{array}{l}* \\
* \\
*\end{array}$ & $\begin{array}{l}* \\
* \\
*\end{array}$ \\
\hline $\begin{array}{l}\text { EMP } \\
\text { EMS } \\
\text { FEMP }\end{array}$ & $*$ & $\begin{array}{l}* \\
*\end{array}$ & $\begin{array}{l}* \\
*\end{array}$ \\
\hline $\begin{array}{l}\text { FEMS } \\
\text { FQDJ } \\
\text { FQF }\end{array}$ & $\begin{array}{l}* \\
* \\
*\end{array}$ & & \\
\hline $\begin{array}{l}\text { FQFC } \\
\text { FQLOW } \\
\text { FQUPR }\end{array}$ & $\begin{array}{l}\text { * } \\
* \\
*\end{array}$ & & \\
\hline $\begin{array}{l}\text { FROOM } \\
\text { HEATLP } \\
\text { HEATUP }\end{array}$ & $\begin{array}{l}* \\
* \\
*\end{array}$ & $\begin{array}{l}* \\
*\end{array}$ & $\begin{array}{l}* \\
*\end{array}$ \\
\hline $\begin{array}{l}\text { HEATVF } \\
\text { HVEFLO } \\
\text { HVEXCN }\end{array}$ & $\begin{array}{l}* \\
* \\
*\end{array}$ & $\begin{array}{l}* \\
* \\
*\end{array}$ & $\begin{array}{l}* \\
* \\
*\end{array}$ \\
\hline $\begin{array}{l}\text { HVEXTT } \\
\text { HVFLOW } \\
\text { HVP }\end{array}$ & $\begin{array}{l}* \\
* \\
*\end{array}$ & $\begin{array}{l}* \\
* \\
*\end{array}$ & $\begin{array}{l}* \\
* \\
*\end{array}$ \\
\hline $\begin{array}{l}\text { MASS } \\
\text { ONTARGET } \\
\text { OPLUME }\end{array}$ & $\begin{array}{l}* \\
*\end{array}$ & $\begin{array}{l}* \\
* \\
*\end{array}$ & $\begin{array}{l}* \\
* \\
*\end{array}$ \\
\hline $\begin{array}{l}\text { PPMDV } \\
\text { QC } \\
\text { QF }\end{array}$ & $*$ & $\begin{array}{l}* \\
* \\
*\end{array}$ & $\begin{array}{l}* \\
* \\
*\end{array}$ \\
\hline $\begin{array}{l}\text { QR } \\
\text { QRADRL } \\
\text { ROHB }\end{array}$ & $\begin{array}{l}* \\
*\end{array}$ & $\begin{array}{l}* \\
* \\
*\end{array}$ & $\begin{array}{l}* \\
* \\
*\end{array}$ \\
\hline $\begin{array}{l}\text { SA } \\
\text { SAU } \\
\text { SS }\end{array}$ & $\begin{array}{l}* \\
* \\
* \\
*\end{array}$ & $\begin{array}{l} \\
* \\
*\end{array}$ & $\begin{array}{l}* \\
* \\
*\end{array}$ \\
\hline
\end{tabular}




\begin{tabular}{|l|c|c|c|}
\hline $\begin{array}{l}\text { Variable Name } \\
\text { (continued) }\end{array}$ & CFAST 2.0.1 & CFAST 1.6.4 & $*$ \\
\hline TBR & $*$ & $*$ & $*$ \\
TE & $*$ & $*$ & $*$ \\
TOXICT & $*$ & $*$ & $*$ \\
\hline TWE & $*$ & $*$ & $*$ \\
TWJ $(1, * *)$ & $*$ & $*$ & $*$ \\
ZZCSPEC & $*$ & $*$ & $*$ \\
\hline ZZGSPEC & $*$ & $*$ & $*$ \\
ZZHLAY & $*$ & $*$ & $*$ \\
ZZHVM & $*$ & $*$ & $*$ \\
\hline ZZHVPR & $*$ & $*$ & $*$ \\
ZZMASS & $*$ & $*$ & $*$ \\
\hline ZZRELP & $*$ & $*$ & $*$ \\
ZZTEMP & $*$ & $*$ & $*$ \\
ZZVOL & $*$ & $*$ & $*$ \\
ZZWTEMP $(*, * 1)$ & $*$ & $*$ & $*$ \\
\hline
\end{tabular}


Table 2. Short Descriptions of the CFAST Output Variables Used in the Comparison Method.

\begin{tabular}{|c|c|c|}
\hline Variable Name & Type & Description \\
\hline AA $(N R, N R, 4)$ & $\mathrm{R} * 8$ & Flow from lower layer to lower layer $(\mathrm{kg} / \mathrm{s})$. \\
\hline AFIRED (NV) & $\mathrm{R} * 8$ & Time history for area of fire $\left(\mathrm{m}^{2}\right)$ \\
\hline APS (NR) & $\mathrm{R} * 8$ & Current area of the specified fire $\left(\mathrm{m}^{2}\right)$. \\
\hline AS (NR,NR,4) & $\mathrm{R} * 8$ & Flow from lower to upper layer $(\mathrm{kg} / \mathrm{s})$. \\
\hline ASL (NR,NR,4) & $\mathrm{R} * 8$ & Entrainment from upper into lower layer $(\mathrm{kg} / \mathrm{s})$. \\
\hline BFLO (MBR) & $\mathrm{R} * 8$ & Mass flow rate through HVAC branch IB $(\mathrm{kg} / \mathrm{s})$. \\
\hline $\mathrm{BW}(\mathrm{NR}, \mathrm{NR}, 4)$ & $\mathrm{R} * 8$ & Width of vent (m) (modified by QCVENT). \\
\hline $\mathrm{CE}(\mathrm{MBR})$ & $\mathrm{R} * 8$ & Conductance of HVAC branch IB. \\
\hline EME (NR) & $\mathrm{R} * 8$ & Plume entrainment rate $(\mathrm{kg} / \mathrm{s})$. \\
\hline EMP (NR) & $\mathrm{R} * 8$ & Pyrolysis rate of the fire source $(\mathrm{kg} / \mathrm{s})$. \\
\hline EMS (NR) & $\mathrm{R} * 8$ & Plume flow rate into the upper layer $(\mathrm{kg} / \mathrm{s})$. \\
\hline FEMP (NR) & $\mathrm{R} * 8$ & Pyrolysis rate of the fire source $(\mathrm{kg} / \mathrm{s})$. \\
\hline FEMS (NR) & $\mathrm{R} * 8$ & Plume flow rate into the upper layer $(\mathrm{kg} / \mathrm{s})$. \\
\hline FQDJ $(\mathrm{NR}, \mathrm{NR}, 4)$ & $\mathrm{R} * 8$ & Size of door jet fire (watts). \\
\hline $\mathrm{FQF}(\mathrm{NR})$ & $\mathrm{R} * 8$ & $\begin{array}{l}\text { Net heat generation rate of a fire into a zone } \\
\text { (Watts). }\end{array}$ \\
\hline $\mathrm{FQFC}(2, \mathrm{NR})$ & $\mathrm{R} * 8$ & $\begin{array}{l}\text { Total convective heat gain }(+) \text { or loss }(-) \text { by a } \\
\text { layer. }\end{array}$ \\
\hline FQLOW (NR) & $\mathrm{R} * 8$ & Lower layer heat release rate. \\
\hline FQUPR (NR) & $\mathrm{R} * 8$ & Upper layer heat release rate. \\
\hline FROOM (NRMX) & $\mathrm{R} * 8$ & $\begin{array}{l}\text { Compartment number to which polygon NRMX is } \\
\text { mapped. }\end{array}$ \\
\hline HEATLP (NR) & $\mathrm{R} * 8$ & $\begin{array}{l}\text { Heat release rate in the plume in the lower layer } \\
\text { (W). }\end{array}$ \\
\hline HEATUP (NR) & $\mathrm{R} * 8$ & $\begin{array}{l}\text { Heat release rate in the plume in the upper layer } \\
\text { (W). }\end{array}$ \\
\hline HEATVF (NR) & $\mathrm{R} * 8$ & $\begin{array}{l}\text { Heat release in a vent (sum of all vents between } \\
\text { compartments). }\end{array}$ \\
\hline
\end{tabular}




\begin{tabular}{|c|c|c|}
\hline Variable name (continued) & Type (continued) & Description (continued) \\
\hline HVEFLO $(2$, MEXT) & $\mathrm{R} * 8$ & $\begin{array}{l}\text { Mass flow into upper <lower> layer of } \\
\text { compartment connected to HVAC external node } \\
\text { IB. }\end{array}$ \\
\hline HVEXCN (MEXT,NS) & $\mathrm{R} * 8$ & $\begin{array}{l}\text { Species concentrations at HVAC external nodes } \\
\left(\mathrm{kg} / \mathrm{m}^{3}\right) \text {. }\end{array}$ \\
\hline HVEXTT (MEXT) & $\mathrm{R} * 8$ & $\begin{array}{l}\text { Temperature of flow through HVAC extemal } \\
\text { node } \mathrm{i} \text {. }\end{array}$ \\
\hline HVFLOW (MNODE,MCON) & $\mathrm{R} * 8$ & $\begin{array}{l}\text { HVFLOW }(i, j) \text { is the mass flow rate to node } i \\
\text { from the } j \text { th node to which it is connected. }\end{array}$ \\
\hline HVP (MNODE) & $\mathrm{R} * 8$ & Relative pressure at HVAC node i. \\
\hline MASS $(2, N R, N S)$ & $\mathrm{R} * 8$ & $\begin{array}{l}\text { Mass in a compartment layer of species i ( } 1 \text { to } \\
\text { NS). }\end{array}$ \\
\hline ONTARGET (NR) & $\mathrm{R} * 8$ & $\begin{array}{l}\text { Absolute radiation from the upper layer to a target } \\
\text { (less ambient). }\end{array}$ \\
\hline OPLUME (3,MXOIN) & $\mathrm{R} * 8$ & $\begin{array}{l}\text { Pyrolysis rate, plume entrainment rate, and plume } \\
\text { flow rate for the "other objects". }\end{array}$ \\
\hline PPMDV $(2, N R, N S)$ & $\mathrm{R} * 8$ & Mass concentration $\left(\mathrm{kg} / \mathrm{m}^{3}\right)$. \\
\hline $\mathrm{QC}(2, \mathrm{NR})$ & $\mathrm{R} * 8$ & Net convective heat loss from a zone (Watts). \\
\hline $\mathrm{QF}(\mathrm{NR})$ & $\mathrm{R} * 8$ & $\begin{array}{l}\text { Net heat generation rate of a fire into a zone } \\
\text { (Watts). }\end{array}$ \\
\hline $\mathrm{QR}(2, \mathrm{NR})$ & $\mathrm{R} * 8$ & Net radiation loss from a zone (Watts). \\
\hline QRADRL & $\mathrm{R} * 8$ & Fraction of heat which leaves a fire as radiation. \\
\hline ROHB (MBR) & $\mathrm{R} * 8$ & Density of gas in HVAC branch IB. \\
\hline $\mathrm{SA}(\mathrm{NR}, \mathrm{NR}, 4)$ & $\mathrm{R} * 8$ & Flow field upper to lower $(\mathrm{kg} / \mathrm{s})$. \\
\hline SAU (NR,NR,4) & $\mathrm{R} * 8$ & Entrainment rate into the upper layer. \\
\hline SS $(\mathrm{NR}, \mathrm{NR}, 4)$ & $\mathrm{R} * 8$ & Flow field from upper to upper layer $(\mathrm{kg} / \mathrm{s})$ \\
\hline TBR (MBR) & $\mathrm{R} * 8$ & $\begin{array}{l}\text { Absolute temperature of gases in HVAC branch } \\
\text { IB. }\end{array}$ \\
\hline $\mathrm{TE}$ & $\mathrm{R} * 8$ & Pyrolysis temperature of the fuel. \\
\hline TOXICT $(2, N R, N S)$ & $\mathrm{R} * 8$ & Conglomeration of stuff for output. \\
\hline TWE (NWAL,NR) & $\mathrm{R} * 8$ & $\begin{array}{l}\text { Temperature of the gas external to a compartment } \\
\text { boundary. }\end{array}$ \\
\hline
\end{tabular}




\begin{tabular}{|c|c|c|}
\hline Variable name (continued) & Type (continued) & Description (continued) \\
\hline TWJ $(1, N R, N W A L)$ & $\mathrm{R} * 8$ & $\begin{array}{l}\text { Surface temperature profile in the boundaries } \\
\text { (ceiling, floor, upper/lower wall). }\end{array}$ \\
\hline ZZCSPEC (NR,2,NS) & $\mathrm{R} * 8$ & $\begin{array}{l}\text { Mass fraction of a species in a layer of a } \\
\text { compartment. }\end{array}$ \\
\hline ZZGSPEC (NR,2,NS) & $\mathrm{R} * 8$ & $\begin{array}{l}\text { ZZGSPEC }(i, j, k) \text { is the amount of species } k \text { in } \\
\text { layer } j \text { in compartment } i \text {. }\end{array}$ \\
\hline ZZHLAY (NR,2) & $\mathrm{R} * 8$ & $\begin{array}{l}\text { ZZHLAY }(\mathrm{i}, \mathrm{j}) \text { is the height of layer } \mathrm{j} \text { in } \\
\text { compartment } \mathrm{i} \text {. }\end{array}$ \\
\hline ZZHVM (MXHVSYS) & $\mathrm{R} * 8$ & Mass of gas in HVAC system ISYS. \\
\hline ZZHVPR (MXHVSYS,NS) & $\mathrm{R} * 8$ & $\begin{array}{l}\text { Amount of product IPROD associated with } \\
\text { HVAC system ISYS. }\end{array}$ \\
\hline ZZMASS (NR,2) & $\mathrm{R} * 8$ & $\begin{array}{l}\text { ZZMASS }(i, j) \text { is the mass of layer } j \text { in } \\
\text { compartment } i \text {. }\end{array}$ \\
\hline $\mathrm{ZZQ}(\mathrm{NR}, 2)$ & $\mathrm{R} * 8$ & $Z Z Q(i, j)$ is the energy of layer $j$ in compartment $i$. \\
\hline ZZRELP (NR) & $\mathrm{R} * 8$ & Pressure relative to POFSET in compartment i. \\
\hline ZZTEMP (NR,2) & $\mathrm{R} * 8$ & $\begin{array}{l}\text { ZZTEMP( } i, j) \text { is the temperature of layer } j \text { in } \\
\text { compartment } i \text {. }\end{array}$ \\
\hline ZZVOL (NR,2) & $\mathrm{R} * 8$ & $\begin{array}{l}\text { ZZVOL }(i, j) \text { is the volume of layer } j \text { in } \\
\text { compartment } i \text {. }\end{array}$ \\
\hline ZZWTEMP (NR,NWAL,1) & $\mathrm{R} * 8$ & $\begin{array}{l}\text { Wall temperature of an inside wall surface in a } \\
\text { compartment. }\end{array}$ \\
\hline
\end{tabular}




\section{Running the Comparison Method Using Two Test Cases.}

\subsection{Description of the Test Cases.}

Two CFAST input data files were selected from the 107 test cases to demonstrate the comparison method. These cases, 1RFURN1.DAT and 3RCORR.DAT, will be described in some detail to provide information helpful in understanding their analyses.

\subsubsection{RFURN1.DAT}

A series of room fire tests with upholstered furniture was carried out by NIST to compare the results with the furniture's behavior when bumed in the open. The room in which the furniture was bumed was of fixed size, but had a window opening that varied in shape and size in the test series. Gypsum board of $16 \mathrm{~mm}$ thickness, attached to steel studs and joists, formed the room's walls and ceiling, while the floor consisted of concrete. In test 1 of this series, the item burned was a love seat. The CFAST input data file 1RFURN1.DAT is a comparison with test number 1 of the series [4]. The complete input data file follows, while information about the interpretation of the input data file is given in reference [1].

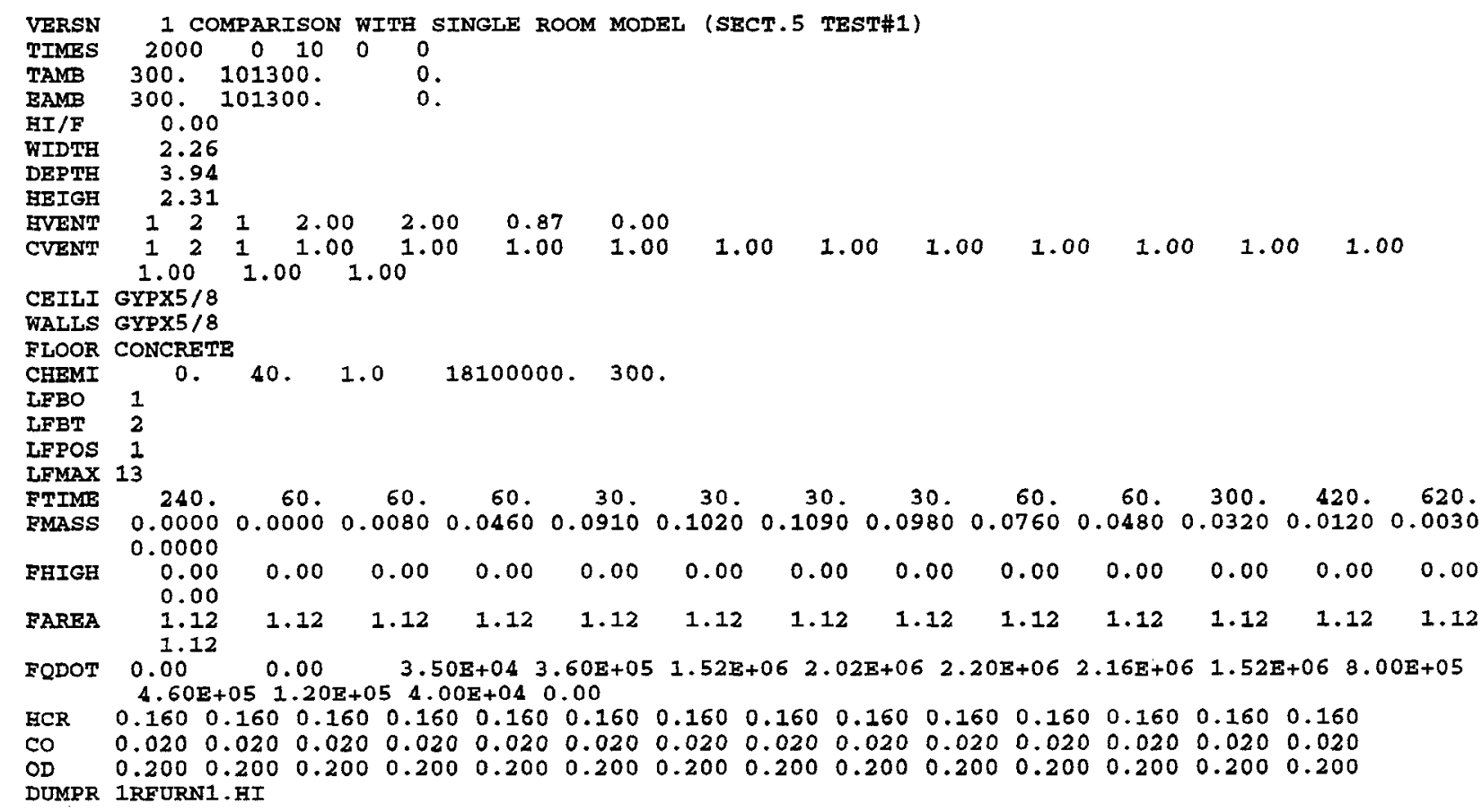

Simplicity is the main advantage of 1RFURN1.DAT, since it describes a one - room scenario with one opening. The good documentation for the example, due to the test series, is an additional bonus. 


\subsubsection{RCORR.DAT}

A more complicated scenario is shown in 3RCORR.DAT. This input data file simulates the conditions in a set of fire experiments using a three-room configuration, where one room represents a small corridor. The rooms were fixed in size throughout the tests, while the fire size and door openings were varied [4]. The fires were always gas burner fires, simplifying the simulation of these scenarios via fire models, since such fires are simple and steady - state. Rate of heat release for the gas fires was set at 100,300 , or $500 \mathrm{~kW}$ during the test series.

3RCORR.DAT replicates one of the $100 \mathrm{~kW}$ fire tests. The complete input data file is:

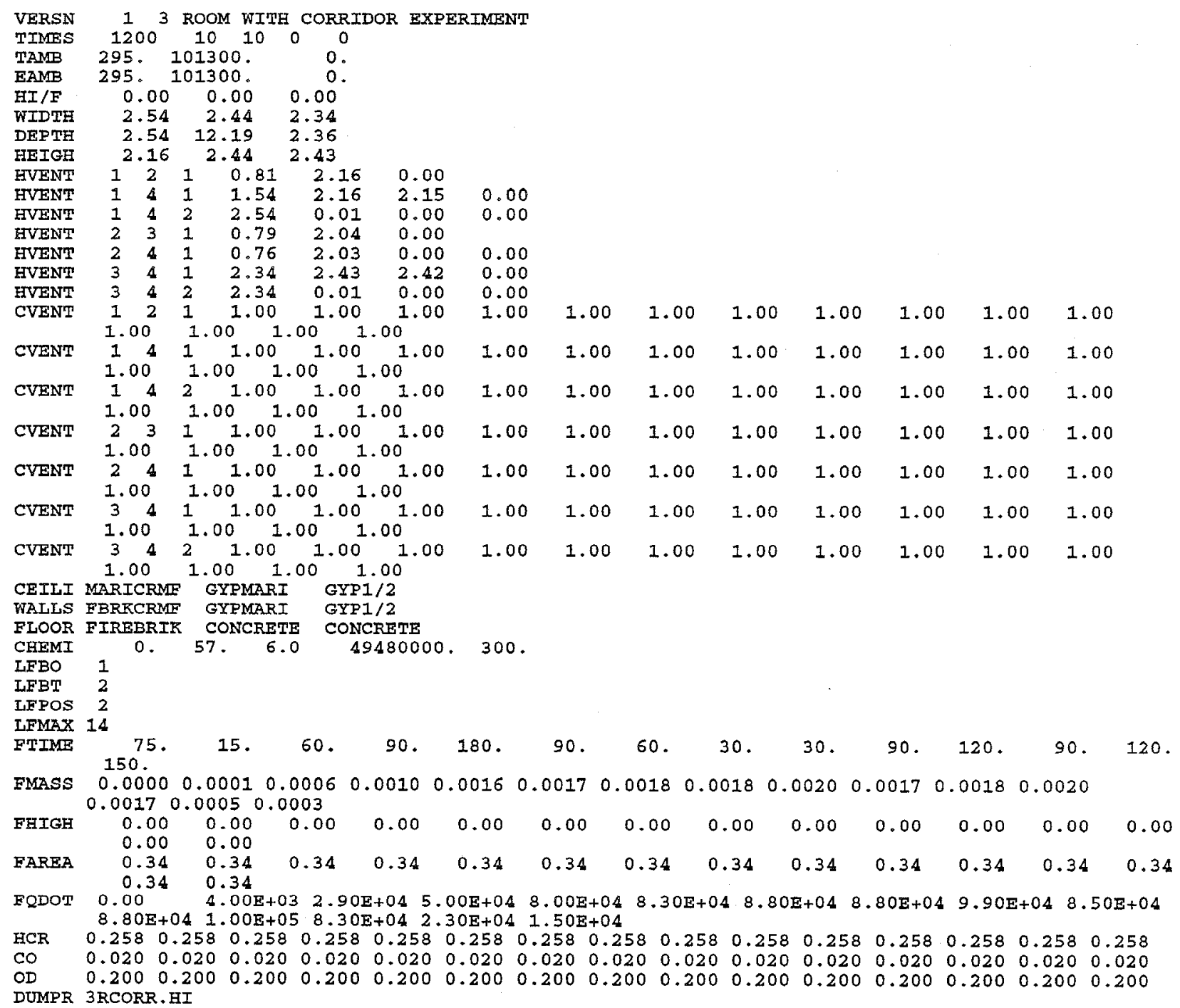

It may be noted that the rate of heat release (FQDOT) in the data file is usually slightly less than 100 
$\mathrm{kW}$. The values chosen are based on measured rates of heat release, as opposed to the rate of $100 \mathrm{~kW}$ supposedly generated by the bumer. The discrepancy is explained in [4].

\subsection{Running the Comparison.}

\subsubsection{Overview.}

1RFURN1.DAT and 3RCORR.DAT were run with two versions of CFAST to demonstrate the mechanics of using the comparison method, and to show the capability of the method to highlight changes in CFAST itself. Four binary history files, four text dump files, two comparison output files, and a comparison summary file were created. The steps will be described at greater length in this section.

It should be noted how file names for each step were chosen in a way that is relatively self documenting. The CFAST version number was included in some names, and the portions of the names after the periods are unique for each type of file throughout the comparison method. If the comparison method had been used to compare CFAST output produced by the same CFAST version, the naming conventions would have been simpler. A naming convention is not mandatory, but it is highly recommended that any user of the method adopt some naming scheme.

Whenever file names are used while running the comparison method, it is best if they refer to files in the same directory as the program that is being run. If they are in other directories, the full path should be supplied in addition to the file name.

\subsubsection{Creating the Binary History Files.}

First, CFAST version 2.0.1 was run with each of the two test input data files to produce binary history files. During this process, it was quickly determined that 3RCORR.DAT did not run under CFAST 2.0.1 since 2 materials, MARICRMF and GYPMARI, are not in the thermal properties file THERMAL.DF for version 2. A new thermal property database file called THER3RCO.DF was created by appending the properties of these materials, taken from the THERMAL.DF file for CFAST 1.6.4, to the THERMAL.DF file for version 2.0.1. The keyword specifying an alternative thermal properties file was placed into 3RCORR.DAT, which was rerun without any complications. The syntax used to create the binary history files was:

and

CFAST 1RFURN1.DAT

CFAST 3RCORR.DAT (with THER3RCO.DF specified as the thermal properties file, only for this run)

to produce the files

and 
respectively.

Next, version 1.4 of the CFAST model was executed with the two test data files to create an additional two binary history files. The syntax, very similar to that of the previous runs, was:

and

$$
\text { CFAST 1RFURN1.DAT }
$$

CFAST 3RCORR. DAT

to produce the files

and

$$
\text { 1RFUR14.HI }
$$

3RCOR14.HI,

respectively.

It may be observed that the names of the four binary history files were created by combining the names of the input data files with the CFAST version number, and adding the standard history file extension .HI. The CFAST user can, by means of the DUMPR line within an input data file, specify the name of the history file created from that input file. Also, in order for the history file to be created, the TIMES line of the input file must contain a nonzero history time interval for the binary history file. More information can be obtained from reference [1].

\subsubsection{Producing the Text Dump Files.}

Version 2.0 .1 of the REPORT program was run to create text dump files from the history files created by CFAST version 2.0.1. The format was:

and

$$
\text { REPORT20 1RFUR201.HI 1RFUR201.ASC }
$$

REPORT20 3RCOR201.HI 3RCOR201.ASC

to produce

and

$$
\text { 1RFUR201.ASC }
$$

3RCOR201.ASC,

respectively.

Next, version 1.4 of the REPORT program produced text dump files from the CFAST version 1.4 history files:

and

$$
\text { REPORT14 1RFUR14.HI 1RFUR14.ASC }
$$


to produce

and

1RFUR14.ASC

3RCOR14.ASC,

respectively.

The text dump file names are identical to those of the history files from which they are generated, except for the .ASC portions after the period. The term ASC is a contraction of ASCII, the common text type in which the text dump files are stored.

\subsubsection{Creating the Comparison Output Files.}

During this step of the comparison method, pairs of text dump files are compared, and their differences stored in comparison output files. In the following pairwise comparisons, the files generated from CFAST version 2.0.1 simulations always appear as the first of the two. When comparing output from different versions of CFAST, adopting such a scheme is helpful, since the CFAST versions of the variable value pairs in each comparison output file will be consistently ordered.

When performing this step, the file VARNAMES.DAT was in the same directory as COMPARE. The standard VARNAMES.DAT was used, with all output variables initially chosen for comparison except for TOXICT (see 2.4.1), and the maximum relative difference criteria set at 0.001 for each variable. The names of all important CFAST output variables were included in VARNAMES.DAT, including those from CFAST version 2.0.1 that were not in version 1.4, and those in version 1.4 that had been discontinued in 2.0.1.

First, the comparison of the CFAST 2.0.1 and 1.4 versions of the text dump files created from 1RFURN1.DAT was performed. The exact syntax used was:

COMPARE 1RFUR201.ASC 1RFUR14.ASC 1R20114.CMP

It may be observed that the comparison output file produced is called 1R20114.CMP, with the name being derived by taking the first two letters of the original input data file, adding the two CFAST versions being compared in their exact order, and ending with .CMP. The CMP is a much shorter form of the term "comparison output file".

Finally, the comparison of the CFAST 2.0.1 and 1.4 versions of the text dump files produced from 3RCORR.DAT was performed. The syntax was:

COMPARE 3RCOR201.ASC 3RCOR14.ASC 3R20114.CMP,

where 3R20114.CMP is the comparison output file. The naming conventions are identical to those 
chosen for 1RFURN1.DAT.

\subsubsection{Producing the Comparison Summary File.}

The final step of the comparison method was to create a comparison summary file, containing summary information from each generated comparison output file. It was first necessary to produce a text file containing the names of all comparison output files to be examined. This file will be termed a script file. The name chosen for the script file was CO20114.SCR, standing for "compare CFAST 2.0.1 with CFAST 1.4", with .SCR denoting script.

The contents of the script file CO20114.SCR consisted of the names of the two comparison output files created by the previous step, one on each line:

Line 1: $\quad$ 1R20114. CMP

Line 2: $\quad 3 R 20114 . \mathrm{CMP}$

The names may appear anywhere within the line, and should refer to files in the same directory as the program COMPINFO.

After the script file CO20114.SCR was created, the comparison summary file CO20114.RES was formed via the following line:

COMPINFO CO20114.SCR CO20114.RES NO

The .RES portion of the comparison summary file name represents "results". It may be argued that .SUM (for "summary") would be a better choice, but the last step of the comparison method contains the "results" that most persons will examine.

Since only 2 comparison output files are being analyzed in this case, the option NO (standing for NO SUMMARY of the major differences, and described in 2.5.1) was chosen when running COMPINFO. Therefore, all range 1 differences appear in the comparison summary file. Much of the generated summary file appears as Appendix B.

\subsection{Analyzing the Results.}

\subsubsection{Overview}

In the following analysis of the two test cases only the comparison summary file, the file produced by the final step of the comparison method, will be examined in depth. Much more information is contained in the two comparison output files, from which the last step gathers information, than is available in the comparison summary file. However, the main thrust of this report is to demonstrate the mechanics of running the comparison method, to explain output from the various steps, and to show how the method can be used to track changes in CFAST output and CFAST versions. It is NOT to perform an exhaustive analysis of all the comparison differences shown within a comparison output 
file. Enough information is given in this report to enable the user to perform such an analysis, with the help of CFAST documentation, and anyone who wishes to examine the comparison output files may do so when performing their own comparisons. In addition, many ways of changing the comparison output file via changes to VARNAMES.DAT have been discussed. These means may be used by the modeler to reduce the size of the comparison output file, using knowledge about what is considered important for the situation at hand. In the sample cases, the comparison output file produced by the 1RFURN1.DAT comparison was 1 megabyte in size, while the one generated by 3RCORR.DAT was 1.8 megabytes. A small section from one of these comparison output files appears as Appendix A. These files are too large for anyone to fully analyze without summarizing via the last step of the comparison method, or reduction via intelligent use of VARNAMES.DAT. The last step of the comparison method also has the advantage that it generates only one possible output per given comparison when the entire method is used without changes. Finally, if something of interest is noted in the comparison summary file, the appropriate comparison output file can always be examined to find the relevant output variables' subscripts and values, and the simulation time steps involved.

After the comparison method was used to find the differences generated by the test cases between the CFAST versions, it was found that a great majority of major differences appearing in the comparison summary file pertained to two variables that differed at almost every time step. A more selective run of the comparison method was performed, with these variables omitted by changing VARNAMES.DAT. An explanation of why these two variables differed appears in section 4.3.2, and justification for their removal from the comparison appears in 4.3.3.

Figures 2 and 3 were prepared by running COMPINFO with the summary option selected to avoid listing the major differences found. These figures also contain results for the two output variables that were later omitted from the comparison method runs, in order to show the full results. After these two variables were removed from the comparison method using VARNAMES.DAT, and new comparison output files created, COMPINFO was run again. In this case, "NO summary" was chosen, and all major differences were listed. A large fraction of the resultant comparison summary file appears as Appendix B. Appendix A contains one time step extracted from one of the comparison output files used to generate Appendix B. Its main purpose is to show the form of the information before it was summarized by the last step of the comparison method. No detailed analysis of this appendix will be performed.

A short recapitulation of the nature and format of Appendix B will be helpful at this point, to familiarize the readers with its overall content and layout, and help guide them to sections under discussion. Appendix B is a large subset of the comparison summary file produced by the last step of the comparison method, COMPINFO. It contains summary information for the two comparison output files, the files produced by running the two test cases under CFAST versions 2.0 .1 and 1.4 and then comparing the results. The test data files were not changed, only the CFAST versions used to produce the output. The first main section of the appendix consists of the summary section for test case 1RFURN1.DAT, with the first part being a listing of major differences found, and the remaining half page showing information for difference ranges 2 through 5. The next main section is the summary section for 3RCORR.DAT, with the first part listing the major differences, and the remaining half page showing the output variables in difference ranges 2 through 5 . The major difference sections for each test case only show some of the time steps for which large differences were actually found; the elimination of some time steps makes the overall comparison summary file easier to understand. The last main section of the appendix is the general summary section, consisting of the information found in both test data files, grouped by the five difference ranges. Within each range, the output is 
arranged by output variable and test case file name, as discussed in 2.5.3.

\subsubsection{Initial Run of the Comparison Method.}

After the initial use of the comparison method, the comparison summary file was examined. It was observed that the great majority of the major differences appearing in this file, for both test cases, were due to the same two output variables. These variables were MASS and ZZRELP. Discussions with the main CFAST developers occurred to leam why these variables differed greatly at practically every time step. It was determined that the reasons for the differences involved changes in the treatment of these output variables between CFAST versions 2.0.1 and 1.4, rather than any fundamental changes in the physics, chemistry, or mathematics of the model.

It was ascertained by examination of the CFAST code, and the talks with CFAST developers, that the output variable MASS is no longer updated in CFAST version 2.0.1 at each simulation time step. It is only given values initially, and not changed afterwards. The values for items formerly covered by the variable MASS are now found in another CFAST output variable. This change occurred after CFAST 1.4 , which contains updated values in MASS.

The variable ZZRELP was the other variable observed to have great differences at every time step of each test case. According to the CFAST developers, ZZRELP is practically always going to be dramatically different between output generated by CFAST 2.0.1 and CFAST 1.4.0. The differences are generated by the effect produced by pressure damping factors in versions of CFAST prior to 1.5. These factors are used to stabilize pressure flow in the solution of differential equations within the model.

The great number of range 1 differences in MASS and ZZRELP may be observed in Figures 2 and 3 , which pertain to 1RFURN1.DAT and 3RCORR.DAT, respectively. For 1RFURN1, around 63 percent of the major differences were generated by these variables, while approximately 95 percent of the major differences in 3RCORR are due to them.

\subsubsection{More Selective Run of the Comparison Method.}

After the information about MASS and ZZRELP was obtained, it was decided to rerun the comparison method with these variables omitted, to better highlight the major differences in the other variables. Since MASS is no longer updated in CFAST 2.0.1, and ZZRELP is always dramatically different between CFAST versions 2.0.1 and 1.4, omission of these two variables was justified. All output references to these variables were removed from the comparison summary file by rerunning the comparison method beginning at the COMPARE step, after modifying VARNAMES.DAT. The $Y$ 's in the lines of this file corresponding to MASS and ZZRELP were changed to N 's. Before the changes, these two lines were:

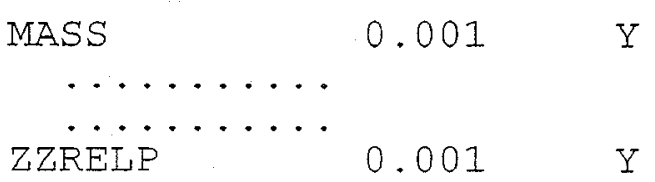


After the changes were performed, the lines became:

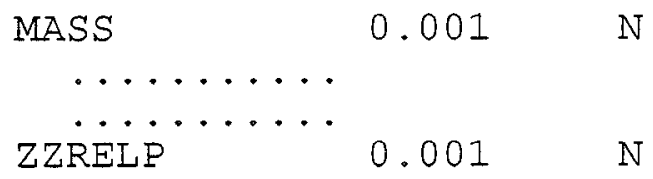

The steps discussed in sections 4.2.4 - 4.2.5 of this report, dealing with the mechanics of running the last two steps of the comparison method for these sample cases, were redone in the same way, after VARNAMES.DAT was modified. Much of the resultant comparison summary file appears as Appendix B.

For the analysis of the differences in CFAST versions 2.0 .1 and 1.4 shown by the test cases, the discussion will be organized as follows. The major (range 1) differences will be covered first, with the variable SAU treated separately. The range 2 differences will be discussed next, followed by the range 3 differences. It has already been explained that most of the initial range 1 differences were due to two variables. After these variables were removed from the comparison, the remaining differences were examined.

The great majority of range 1 differences in the 1RFURN1.DAT comparison summary section were due to the variables PPMDV and ZZGSPEC. Only a subset of these two variables actually contributed to the range 1 differences; the four differing items were PPMDV $(2,1,8)$, ZZGSPEC $(1,2,3)$, ZZGSPEC $(1,2,8)$, and ZZGSPEC $(1,2,9)$. In all four cases, the CFAST 2.0.1 variable values shown in the range 1 differences were initially smaller than the corresponding CFAST 1.4 values for these items, and then dropped quickly and steadily. The CFAST 1.4 values dropped only slowly. Although the four items differed by approximately 2 orders of magnitude when they initially appeared in range 1 , their values at the end of the simulation differed by at least 16 orders of magnitude. Due to the nature of the output variables PPMDV and ZZGSPEC, which contain values for mass concentration and species respectively, it is practically certain that the observed changes are due to major enhancements in chemistry placed into the CFAST model between versions 1.4 and 2.0.1.

There was also a general trend in the major differences found in the 3RCORR.DAT comparison summary section. It was determined that all CFAST output variables with range 1 differences in this test case pertain to phenomena at active horizontal flow vents. Examination of the comparison output file from which this summary section originated provided the probable solution. The interface heights differed significantly between the CFAST 2.0.1 and 1.4 runs at the simulation times where the major differences occurred. This would certainly have a major effect on phenomena at horizontal flow vents that extend into the upper layer. Also, major changes occurred between CFAST versions 2.0.1 and 1.4 in generalized vent flow, including horizontal flow.

A misleading contributor to the observed range 1 differences is the variable SAU, the entrainment rate into the upper layer. In all major differences due to this variable in the sample comparison, the second subscript of the variable has a value corresponding to the outside. The outside, in the zone model CFAST, is only considered to have a lower layer. No mixing of air with the outside is permitted, since the outside's properties cannot be changed. A second subscript value for SAU that refers to the outside is therefore nonsensical in this case, and may be ignored. Due to the way the subscripts are generated by REPORTnn for horizontal flow vents, and then used by the COMPARE step of the comparison method independently, fixing the second subscript problem for the variable SAU is not 
trivial to do.

The range 2 differences in the comparison summary file do not show any variables with numerous differences in this range, except for PPMDV and ZZGSPEC in the test case 3RCORR.DAT. The differences in these variables are due to the same reason these variables had major differences for 1RFURN1.DAT; the chemistry built into CFAST 2.0.1 is much better than that contained in version 1.4 .

Examination of the range 3 differences within the comparison summary file showed that the variables TWE and QRADRL were in this range often for both test cases, and that in all these occurrences one member of the compared pairs of values was 0 . This phenomena merited examination of the comparison output files. Values for QRADRL were always equal to the value 0.15 in CFAST 2.0.1 output in the comparison output files, but were always 0 in CFAST 1.4. These values may be observed in the time step, extracted from a comparison output file, shown in Appendix A. It was learned that QDRADRL remains constant since it is the fraction of heat which leaves the fire as radiation, and is either explicitly chosen in the input file, or defaults to a known value. In neither test data file was QRADRL explicitly assigned a value. In CFAST 2.0.1 it defaults to 0.15 if not specified, which was the value found. In CFAST 1.4 it defaulted to 0 , the value in the comparison output file. Since QRADRL remains constant throughout a CFAST run, and has a known value, it need not be included in the comparison method. Also, it was learned that the variable TWE is no longer used in CFAST 2.0.1, and therefore its differences are unimportant. The variables TWE and QRADRL can be seen in the range 3 output sections of Figures 2 and 3 , showing that one member of the compared pairs of values is always 0 .

In general, any variables in a difference range higher than 3 show very good agreement between compared runs, since none of their compared differences can be greater than 0.5 . These variables need not be discussed. The only time that this situation is of concem is when the modeler expects much greater differences in a CFAST output variable, or when even minor differences should not occur.

The information about usage of variables such as MASS, TWE, QRADRL, and TWJ in CFAST 2.0.1, discovered through analysis of these test cases, will be used to create a new REPORT20 program, and will be incorporated into future versions of REPORTnn. The new versions of these programs will not place the redundant and obsolete output variables into the text dump files that they produce. Therefore, it will be impossible to compare these variables even if they are listed in VARNAMES.DAT, and selected with the "Y" option. Although no longer used starting in CFAST 2.0.1, these variables were used in previous versions, and therefore versions of REPORTnn before 2.0.1 will not be changed. The variables mentioned here as no longer being in CFAST 2.0.1 were not removed from Table 1 for that model version, since they still exist in the model, but do not have values that are updated correctly. 


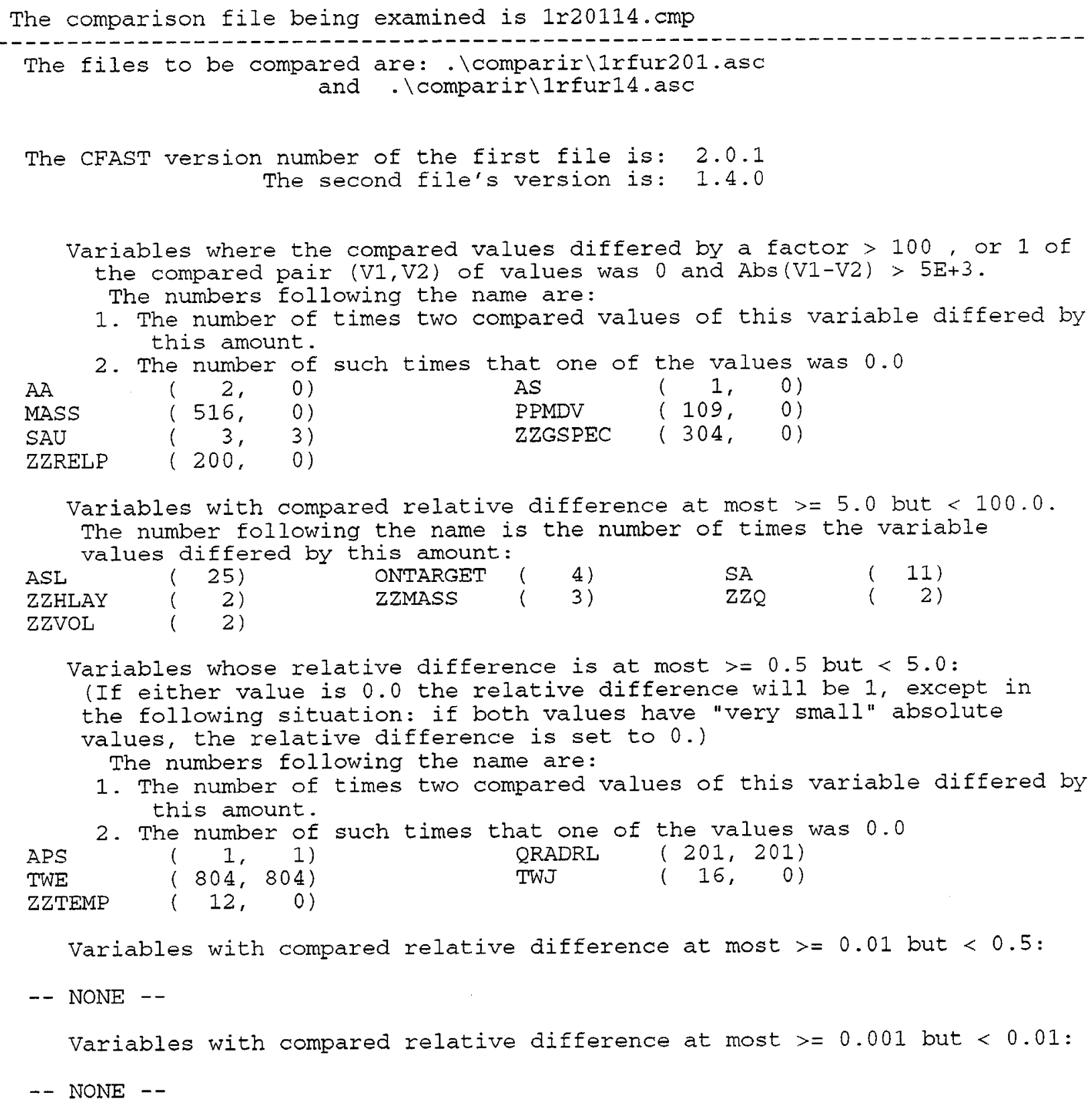

Variables whose relative difference is at most $>=0.5$ but $<5.0$ : (If either value is 0.0 the relative difference will be 1 , except in the following situation: if both values have "very small" absolute values, the relative difference is set to 0.)

The numbers following the name are:

1. The number of times two compared values of this variable differed by this amount.

2. The number of such times that one of the values was 0.0

$\begin{array}{lrrr}\text { APS } & (1,1) & \text { QRADRL } & (201,201) \\ \text { TWE } & (804,804) & \text { TWJ } & (16,1\end{array}$

Variables with compared relative difference at most $>=0.01$ but $<0.5$ :

-- NONE --

Variables with compared relative difference at most $>=0.001$ but $<0.01$ :

- NONE - -

\section{Figure 2. COMPINFO Summary of Differences Between Output from Two Versions of CFAST}

Run with 1RFURN1.DAT. 


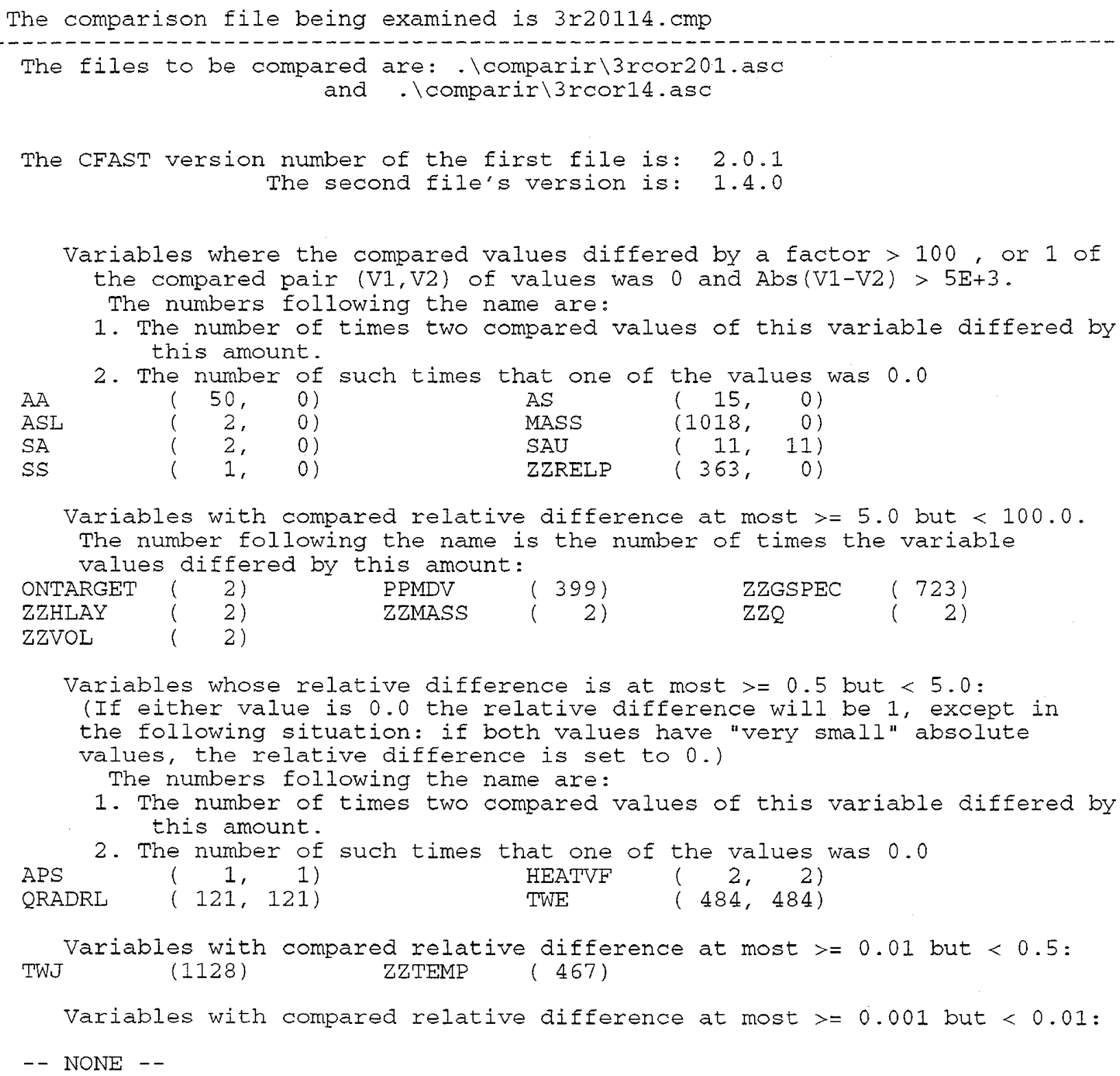

Variables whose relative difference is at most $>=0.5$ but $<5.0$ :

(If either value is 0.0 the relative difference will be 1 , except in

the following situation: if both values have "very small" absolute

values, the relative difference is set to 0. .)

The numbers following the name are:

1. The number of times two compared values of this variable differed by this amount.

2. The number of such times that one of the values was 0.0

Figure 3. COMPINFO Summary of Differences Between Output from Two Versions of CFAST Run with 3RCORR.DAT. 


\section{Conclusions.}

The comparison method can already compare the output of two or more CFAST runs, extract the important output variable values in each run, and produce information about the differences in these values. This information can be very detailed, showing every difference between selected pairs of runs, or can be summarized. Customization of the method's sensitivity and output variables to be compared is already possible. The relative difference calculation in the method produces results independent of order of comparison of the two text dump files, and is used to successfully subdivide variable differences into five different ranges. Nonetheless, there are ways in which the comparison method can be improved and generalized.

The comparison method will be used, along with the CFAST input test cases, to track any changes to CFAST whenever a substantial change occurs to the model. This process has already been performed, and lends itself to further streamlining. In the short term, it would be advantageous to automate running the CFAST test data files through the entire comparison method whenever a significant change is made to CFAST. The automation of this process on a workstation would be simple. The only change required to the programming code of the comparison method would be the creation of a new version of REPORTnn corresponding to the new CFAST version. After the automated run is performed, the summary at the end of the COMPINFO output would show which output variables were affected by the changes in CFAST, in which data files, and approximately by how much. Whenever a major change is made to CFAST, using all of the test cases would be best, but a judiciously chosen subset could be run more easily and hence encourage more frequent use of the comparison method for this purpose.

The method used to calculate the difference criterion does not knowledgeably differentiate between the variables. It does permit the user of the comparison method to change the criteria for each variable in VARNAMES.DAT (see 2.4.2). Since a different definition of what constitutes a "significant" difference can be chosen for each output variable, more accurate comparisons can theoretically be made. The best way to utilize this ability to target significance criteria is to produce a table containing such criteria for each of the CFAST output variables in the comparison method, with the criteria produced by means of a consensus process. Eventually, it may be preferable to use an absolute difference calculation, rather than the current relative one. An absolute difference criterion would require more information about the ranges of values each output variable attains, but this information may also be attained via a consensus. Better handling of cases where one compared value is 0 should also be investigated. The statistic currently used to produce a relative difference value yields 1 whenever this situation occurs. The table of significance criteria for each variable, produced by consensus, could also be used in this situation to provide better information for the calculation, since more information would be available about each variable. Establishment of an absolute difference criterion would eliminate this problem entirely.

A mechanism is also needed to subdivide intelligently the CFAST output variables into their components to extract more information from a comparison. An output variable may contain subscripts that denote the fire species whose values are being stored for the simulation time step, or the room under examination, the vent being considered, etc. A species such as oxygen is always referenced by the same subscript number, as is a room or vent in a particular run. It is therefore possible to compare changes in a particular species between runs, or in a particular room, and to 
present the differences in terms of phenomena. This is a more general concept than comparing output variable names, and would do most of the analysis work that a human being currently must do when performing a comparison.

Finally, the current method of implementing changes to the list of output variables in REPORTnn is somewhat cumbersome, and should eventually be streamlined. The process of comparing output variable names can be made more general to handle situations such as the reordering of subscripts in a variable (TOXICT in CFAST 2.0 is an example where this capability would be useful), the renaming of a variable, etc. The use of mapping functions to track name changes of output variables and subscript changes within the variable would be one approach. Comparison of output between two versions of CFAST where such changes have occurred would be simpler. This ability to compare general CFAST output variable names would lead to a very powerful increase in the comparison method's capability; with only slight extension, it would be possible to compare other fire models' output in a fashion similar to CFAST. The extension would primarily consist of a published format for the text dump file, and the addition of a step to fire models that stores output in this format. Once the tracking of names of fire model output variables has been generalized, and a general format for fire model output selected, the output of differing fire models could be compared using the method discussed in this report. 


\section{Acknowledgements}

The overall approach for the comparison method was suggested by Richard Peacock of the Fire Modeling Group, of the Building and Fire Research Laboratory. Other very useful help was received from Walter Jones, Paul Reneke, Rebecca Portier, and Glenn Forney of the same group. Ms. Rebecca Portier generated the table appearing as Table 2. 


\section{References}

[1] Peacock, R. D., Jones, W. W., Forney, G. P., Reneke, P., Portier, R., CFAST, the Consolidated Model of Fire and Smoke Transport, National Institute of Standards and Technology, Technical Note 1299 (1992).

[2] Jones, W. W., A Multicompartment Model for the Spread of Fire, Smoke and Toxic Gases, Fire Safety Journal, 9, 55 (1985).

[3] Forney, G. P., and Cooper, L. Y., The Consolidated Compartment Fire Model (CCFM) Computer Application CCFM.VENTS - Part II: Software Reference Guide, National Institute of Standards and Technology Internal Report 90-4343 (1990).

[4] Peacock, R. D., Davis, S., Babrauskas, V., Data for Room Fire Model Comparisons, J. Res. Natl. Inst. Stand. Technol., 96,411 (1991). 


\section{Appendix A. One Time Step from the Comparison Output File Produced by the 3RCORR.DAT Sample Case.}

This appendix consists of one time step from a comparison output file. To produce the file, two CFAST runs were initially performed, creating binary history files containing values of each CFAST output variable for every simulation time step. The important output variable values in each history file were placed into text dump files. These two files were compared, time step by time step, and the differences placed into the comparison output file.

The format of the shown time step is as follows. The simulation time for the CFAST information being compared is given first. In each of the following lines, the first item is a CFAST variable name, followed by $0-3$ subscript(s) uniquely identifying the current values. The variable's value in the first text dump file is next, followed by the value in the second dump file. The last item in a line is the relative difference, computed as defined in section $\mathbf{2 . 4 . 2}$. For more information about the background of this appendix, see 4.2.4 and 4.3.1.

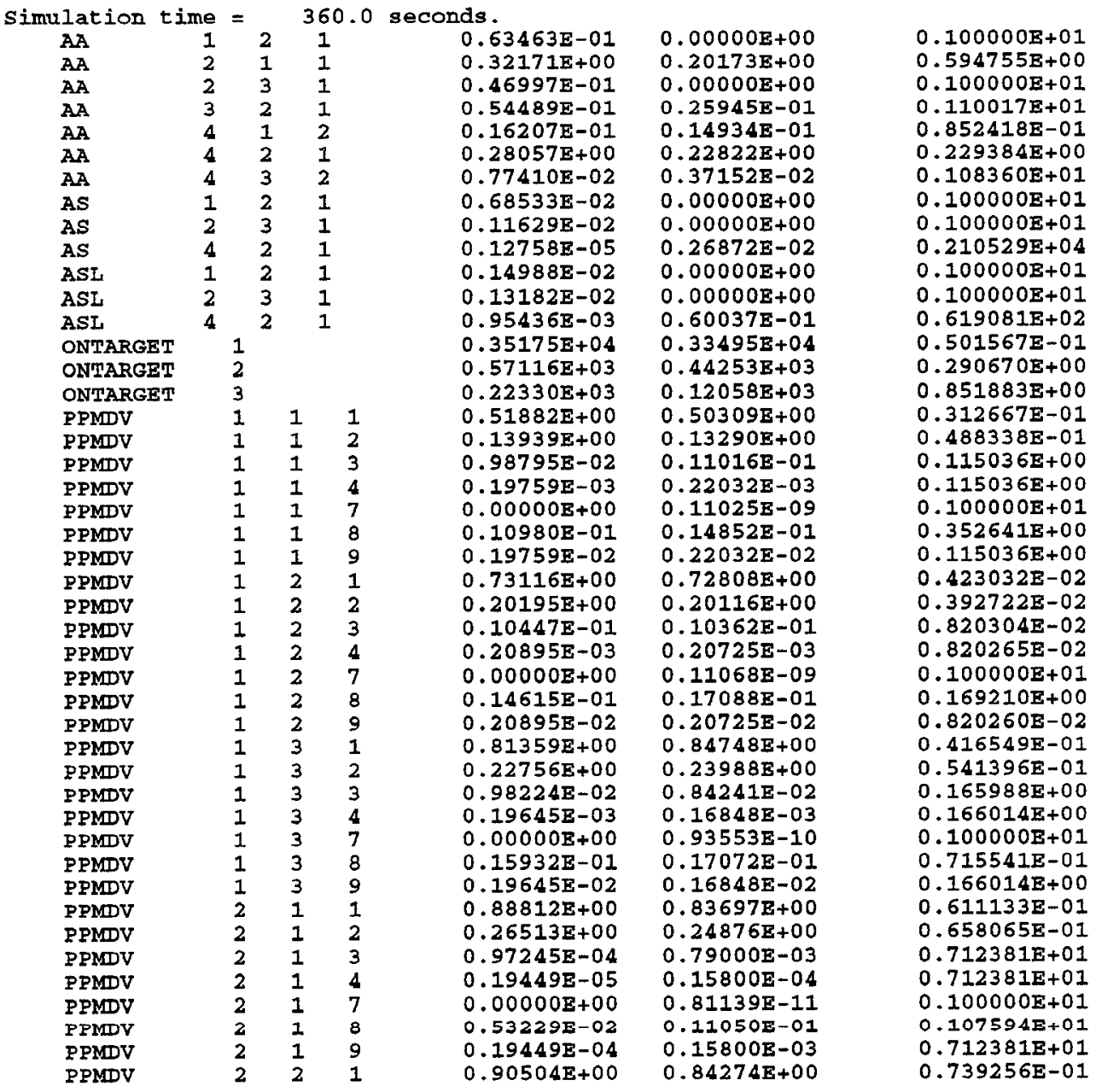




\begin{tabular}{|c|c|c|c|c|c|c|}
\hline PPMDV & 2 & 2 & 2 & $0.27014 \mathrm{E}+00$ & $0.24987 E+00$ & $0.811221 E-01$ \\
\hline PPMDV & 2 & 2 & 3 & $0.12122 \mathrm{E}-03$ & $0.11817 \mathrm{E}-02$ & $0.874839 \mathrm{E}+01$ \\
\hline PPMDV & 2 & 2 & 4 & $0.24244 \mathrm{E}-05$ & $0.23634 \mathrm{E}-04$ & $0.874839 E+01$ \\
\hline PPMDV & 2 & 2 & 7 & $0.00000 \mathrm{E}+00$ & $0.12644 \mathrm{E}-10$ & $0.1000001+01$ \\
\hline PPMDV & 2 & 2 & 8 & $0.47744 \mathrm{E}-02$ & $0.11424 \mathrm{E}-01$ & $0.139276 \mathrm{E}+01$ \\
\hline PPMDV & 2 & 2 & 9 & $0.24244 E-04$ & $0.23634 \mathrm{E}-03$ & $0.874839 E+01$ \\
\hline PPMDV & 2 & 3 & 1 & $0.90475 \mathrm{E}+00$ & $0.89873 E+00$ & $0.669835 E-02$ \\
\hline PPMDV & 2 & 3 & 2 & $0.26999 \mathrm{E}+00$ & $0.26840 E+00$ & $0.592393 E-02$ \\
\hline PPMDV & 2 & 3 & 3 & $0.16811 \mathrm{E}-03$ & $0.31794 E-04$ & $0.428748 \mathrm{E}+01$ \\
\hline PPMDV & 2 & 3 & 4 & $0.33621 \mathrm{E}-05$ & $0.63586 \mathrm{z}-06$ & $0.428748 \mathrm{E}+01$ \\
\hline PPMDV & 2 & 3 & 8 & $0.79051 \mathrm{E}-02$ & $0.11237 \mathrm{E}-01$ & $0.421487 \mathrm{E}+00$ \\
\hline PPMDV & 2 & 3 & 9 & $0.33621 \mathrm{E}-04$ & $0.63588 \mathrm{E}-05$ & $0.428732 E+01$ \\
\hline QRADRI & & & & $0.15000 \mathrm{OE}+00$ & $0.00000 E+00$ & $0.100000 E+01$ \\
\hline $\mathbf{S A}$ & 1 & 4 & . & $0.20989 \mathrm{E}-01$ & $0.21300 \mathrm{E}-01$ & $0.148172 \mathrm{~F}-01$ \\
\hline$S A$ & 2 & 1 & - & $0.85664 \mathrm{~B}-02$ & $0.18692 \mathrm{E}-01$ & $0.118201 E+01$ \\
\hline$S A$ & 2 & 4 & 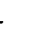 & $0.26505 \mathrm{~F}+00$ & $0.23365 \mathrm{E}+00$ & $0.134389 \mathrm{E}+00$ \\
\hline$S A$ & 3 & 2 & - & $0.40048 E-01$ & $0.47875 E-01$ & $0.195440 \mathrm{E}+00$ \\
\hline$S A$ & 3 & 4 & - & $0.26612 \mathrm{E}-01$ & $0.13934 E-01$ & $0.909861 \mathrm{E}+00$ \\
\hline SAU & 1 & 4 & - & $0.55397 \mathrm{E}+09$ & $0.55247 \mathrm{E}+09$ & $0.271502 \mathrm{E}-02$ \\
\hline SAU & 2 & 1 & - & $0.67684 F-02$ & $0.15736 \mathrm{E}-01$ & $0.132492 \mathrm{E}+01$ \\
\hline SAUU & 2 & 4 & . & $0.77562 E+09$ & $0.71761 \mathrm{z}+09$ & $0.808378 \mathrm{E}-01$ \\
\hline SAU & 3 & 2 & 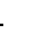 & $0.31278 E-01$ & $0.12595 \bar{E}+00$ & $0.302679 \mathrm{E}+01$ \\
\hline$S A U$ & 3 & 4 & 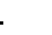 & $0.37022 E+09$ & $0.27731 z+09$ & $0.335040 \mathrm{E}+00$ \\
\hline SS & 1 & 2 & 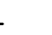 & $0.26391 \mathrm{E}+00$ & $0.26827 \Xi+00$ & $0.165207 \mathrm{E}-01$ \\
\hline ss & 2 & 1 & 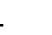 & $0.60795 \mathrm{E}-02$ & $0.13409 E-01$ & $0.120561 \mathrm{E}+01$ \\
\hline SS & 2 & 3 & 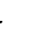 & $0.10540 E+00$ & $0.78454 E-01$ & $0.343462 \mathrm{E}+00$ \\
\hline ss & 3 & 2 & . & $0.40938 \mathrm{E}-01$ & $0.18679 \mathrm{E}-01$ & $0.119166 \mathrm{E}+01$ \\
\hline TWE & 1 & 4 & & $0.00000 \mathrm{E}+00$ & $0.29500 \mathrm{E}+03$ & $0.100000 E+01$ \\
\hline TWE & 2 & 4 & & $0.00000 E+00$ & $0.29500 E+03$ & $0.100000 E+01$ \\
\hline TWE & 3 & 4 & & $0.00000 \mathrm{E}+00$ & $0.29500 \mathrm{E}+03$ & $0.100000 \mathrm{E}+01$ \\
\hline TWE & 4 & 4 & & $0.00000 \mathrm{E}+00$ & $0.29500 \mathrm{E}+03$ & $0.100000 \mathrm{E}+01$ \\
\hline TWJ & 1 & 1 & 1 & $0.41141 \mathrm{E}+03$ & $0.42230 \mathrm{E}+03$ & $0.264699 \mathrm{E}-01$ \\
\hline TWJ & 1 & 1 & 2 & $0.30707 \mathrm{E}+03$ & $0.40742 \mathrm{E}+03$ & $0.326798 \mathrm{E}+00$ \\
\hline TWJ & 1 & 1 & 3 & $0.41975 \mathrm{E}+03$ & $0.39348 E+03$ & $0.667632 \mathrm{E}-01$ \\
\hline TW & 1 & 1 & 4 & $0.33114 \mathrm{E}+03$ & $0.38057 \mathrm{E}+03$ & $0.149272 \mathrm{E}+00$ \\
\hline TWJ & 1 & 2 & 1 & $0.31739 \mathrm{E}+03$ & $0.31578 E+03$ & $0.509854 \mathrm{E}-02$ \\
\hline TWJ & 1 & 2 & 2 & $0.29575 E+03$ & $0.31345 \mathrm{E}+03$ & $0.598479 \mathrm{E}-01$ \\
\hline TWJ & 1 & 2 & 3 & $0.31480 \bar{B}+03$ & $0.31129 \mathrm{E}+03$ & $0.112756 \mathrm{E}-01$ \\
\hline TWJ & 1 & 2 & 4 & $0.29975 E+03$ & $0.30931 \mathrm{E}+03$ & $0.318932 \mathrm{E}-01$ \\
\hline TWJ & 1 & 3 & 1 & $0.30357 \mathrm{E}+03$ & $0.30028 \mathrm{E}+03$ & $0.109565 \mathrm{E}-01$ \\
\hline TWU & 1 & 3 & 2 & $0.29524 \mathrm{E}+03$ & $0.29993 E+03$ & $0.158854 \mathrm{E}-01$ \\
\hline TWJ & 1 & 3 & 3 & $0.30255 \mathrm{E}+03$ & $0.29960 \mathrm{E}+03$ & $0.984640 \mathrm{E}-02$ \\
\hline TWJ & 1 & 3 & 4 & $0.29634 \mathrm{E}+03$ & $0.29929 \mathrm{E}+03$ & $0.995482 \mathrm{E}-02$ \\
\hline ZZGSPEC & 1 & 1 & 1 & $0.18215 \mathrm{E}+01$ & $0.22565 \mathrm{E}+01$ & $0.238814 \mathrm{E}+00$ \\
\hline ZZGSPEC & 1 & 1 & 2 & $0.48938 \mathrm{E}+00$ & $0.59612 \mathrm{E}+00$ & $0.218113 \mathrm{E}+00$ \\
\hline ZZGSPEC & 1 & 1 & 3 & $0.34686 \mathrm{E}-01$ & $0.49406 \mathrm{E}-01$ & $0.424379 \mathrm{E}+00$ \\
\hline ZZGSPEC & 1 & 1 & 4 & $0.69372 \mathrm{E}-03$ & $0.98811 \mathrm{E}-03$ & $0.424364 \mathrm{E}+00$ \\
\hline ZZGSPEC & 1 & 1 & 7 & $0.00000 E+00$ & $0.59424 E-09$ & $0.100000 \mathrm{E}+01$ \\
\hline ZZGSPEC & 1 & 1 & 8 & $0.38550 \mathrm{E}-01$ & $0.66611 \mathrm{E}-01$ & $0.727912 \mathrm{E}+00$ \\
\hline ZZGSPEC & 1 & 1 & 9 & $0.69372 \mathrm{E}-02$ & $0.98811 \mathrm{E}-02$ & $0.424364 \mathrm{E}+00$ \\
\hline ZZGSPEC & 1 & 2 & 1 & $0.92583 E+01$ & $0.79130 \mathrm{E}+01$ & $0.170011 E+00$ \\
\hline ZZGSPEC & 1 & 2 & 2 & $0.27639 \mathrm{E}+01$ & $0.23519 E+01$ & $0.175177 \mathrm{E}+00$ \\
\hline ZZGSPEC & 1 & 2 & 3 & $0.10137 \mathrm{E}-02$ & $0.74697 \mathrm{E}-02$ & $0.636875 \mathrm{E}+01$ \\
\hline ZZGSPEC & 1 & 2 & 4 & $0.20275 \mathrm{~F}-04$ & $0.14939 \mathrm{E}-03$ & $0.636819 \mathrm{E}+01$ \\
\hline ZZGSPEC & 1 & 2 & 7 & $0.00000 E+00$ & $0.17672 \mathrm{E}-09$ & $0.100000 \mathrm{E}+01$ \\
\hline ZZGSPEC & 1 & 2 & 8 & $0.55490 \mathrm{E}-01$ & $0.10447 \mathrm{E}+00$ & $0.882682 \mathrm{E}+00$ \\
\hline ZZGSPEC & 1 & 2 & 9 & $0.20275 E-03$ & $0.14939 \mathrm{E}-02$ & $0.636819 \mathrm{E}+01$ \\
\hline ZZGSPEC & 2 & 1 & 1 & $0.19956 \mathrm{E}+02$ & $0.24155 \mathrm{E}+02$ & $0.210413 \mathrm{E}+00$ \\
\hline ZZGSPEC & 2 & 1 & 2 & $0.55120 \mathrm{E}+01$ & $0.66739 \mathrm{~g}+01$ & $0.210795 E+00$ \\
\hline ZZGSPEC & 2 & 1 & 3 & $0.28515 \mathrm{E}+00$ & $0.34380 E+00$ & $0.205681 \mathrm{E}+00$ \\
\hline ZZGSPEC & 2 & 1 & 4 & $0.57030 \mathrm{E} \sim 02$ & $0.68761 \mathrm{E}-02$ & $0.205699 \mathrm{E}+00$ \\
\hline ZZGSPEC & 2 & 1 & 7 & $0.00000 \mathrm{E}+00$ & $0.37721 \mathrm{E}-08$ & $0.100000 \mathrm{E}+01$ \\
\hline ZZGSPEC & 2 & 1 & 8 & $0.39890 \mathrm{E}+00$ & $0.56693 \mathrm{E}+00$ & $0.421233 \mathrm{E}+00$ \\
\hline ZZGSPEC & 2 & 1 & 9 & $0.57030 \mathrm{E}-01$ & $0.68761 \mathrm{E}-01$ & $0.205699 \mathrm{E}+00$ \\
\hline ZZGSPEC & 2 & 2 & 1 & $0.40981 E+02$ & $0.33196 \mathrm{E}+02$ & $0.234516 E+00$ \\
\hline $\begin{array}{l}\text { ZZGSPEC } \\
\text { ZZGSPEC }\end{array}$ & $\begin{array}{l}2 \\
2\end{array}$ & $\begin{array}{l}2 \\
2\end{array}$ & $\begin{array}{l}2 \\
3\end{array}$ & $\begin{array}{l}0.12232 \mathrm{E}+02 \\
0.54890 \mathrm{E}-02\end{array}$ & $\begin{array}{l}0.98425 \mathrm{E}+01 \\
0.46546 \mathrm{E}-01\end{array}$ & $\begin{array}{l}0.242774 E+00 \\
0.747987 E+01\end{array}$ \\
\hline ZZGSPEC & 2 & 2 & 4 & $0.10978 \mathrm{E}-03$ & $0.93092 \mathrm{E}-03$ & $0.747987 \Xi+01$ \\
\hline ZZGSPEC & 2 & 2 & 7 & $0.00000 \mathrm{E}+00$ & $0.59806 \mathrm{E}-09$ & $0.1000005+01$ \\
\hline ZZGSPEC & 2 & 2 & 8 & $0.21619 \mathrm{E}+00$ & $0.45001 \mathrm{E}+00$ & $0.108155 \mathrm{E}+01$ \\
\hline ZZGSPEC & 2 & 2 & 9 & $0.10978 \mathrm{E}-02$ & $0.93092 E-02$ & $0.747987 E+01$ \\
\hline ZZGSPEC & 3 & 1 & 1 & $0.49205 \mathrm{E}+01$ & $0.80605 \mathrm{E}+01$ & $0.638147 \mathrm{E}+00$ \\
\hline ZZGSPEC & 3 & 1 & 2 & $0.13763 \mathrm{~B}+01$ & $0.22815 E+01$ & $0.657706 \mathrm{E}+00$ \\
\hline ZZGSPEC & 3 & 1 & 3 & $0.59405 E-01$ & $0.80125 E-01$ & $0.348792 \mathrm{E}+00$ \\
\hline ZZGSPEC & 3 & 1 & 4 & $0.11881 \mathrm{E}-02$ & $0.16025 \mathrm{E}-02$ & $0.348792 \mathrm{E}+00$ \\
\hline ZZGSPEC & 3 & 1 & 7 & $0.00000 \mathrm{E}+00$ & $0.98982 \mathrm{E}-09$ & $0.100000 E+01$ \\
\hline ZZGSPEC & 3 & 1 & 8 & $0.96359 \mathrm{E}-01$ & $0.16238 \mathrm{E}+00$ & $0.685157 E+00$ \\
\hline ZZGSPEC & 3 & 1 & 9 & $0.11881 \mathrm{E}-01$ & $0.16025 \mathrm{E}-01$ & $0.348792 E+00$ \\
\hline
\end{tabular}




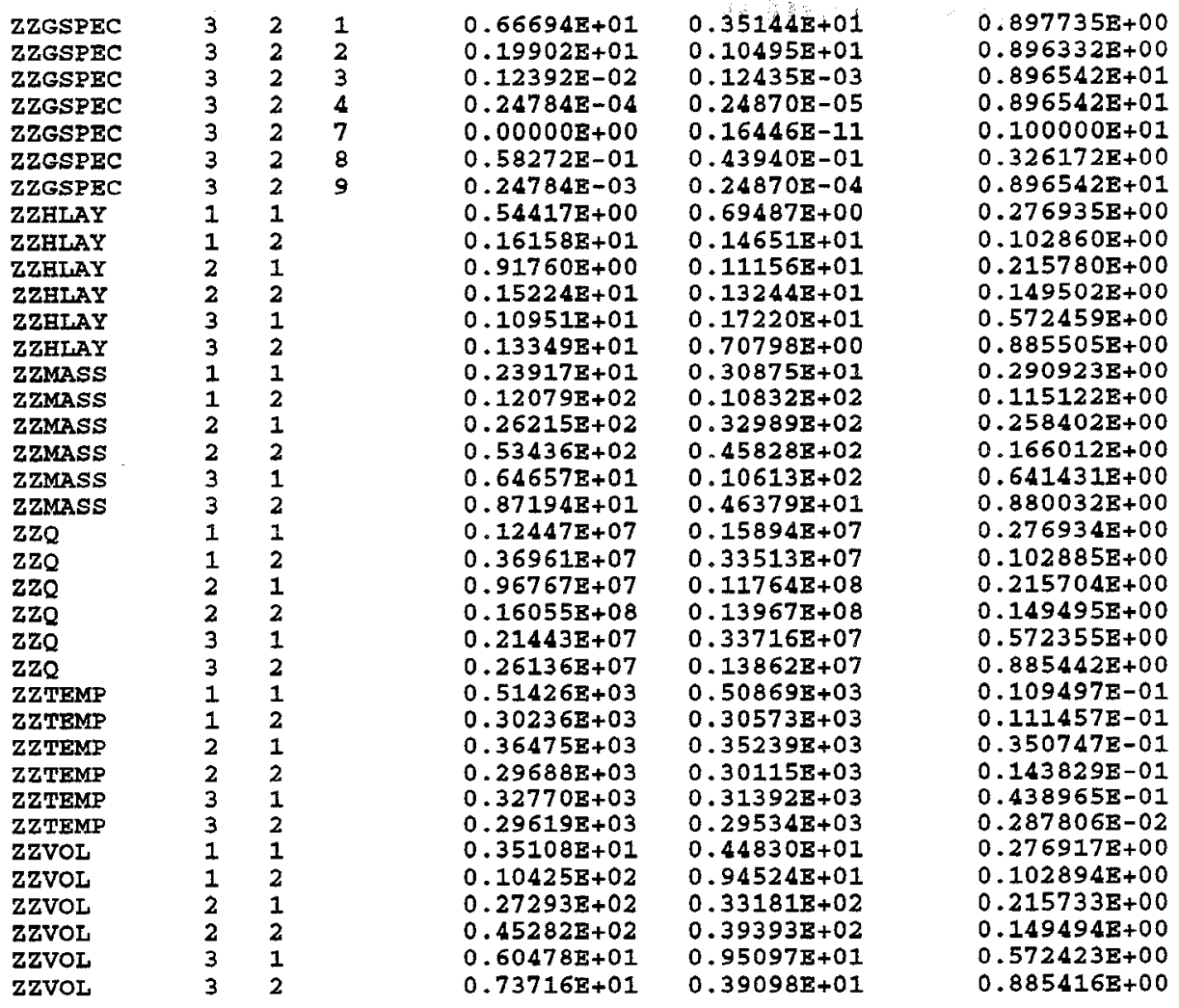




\section{Appendix B. COMPINFO Output for 1RFURN1.DAT and 3RCORR.DAT runs, Comparison Between CFAST 1.4 and 2.0.1}

This appendix is a large subset of a comparison summary file produced by the last step of the comparison method, COMPINFO. The appendix contains summary information for two comparison output files. These files were produced by running two test cases under CFAST versions 2.0.1 and 1.4 and then comparing the results. The input data files were not changed, only the CFAST versions used to produce the output. For more information about the background of the two test cases, and the comparison summary file shown, see 4.3.1 - 4.3.3. The format of a comparison summary file is described at length in 2.5.3.

The first main section of the appendix consists of the summary section for test case 1RFURN1.DAT, with the first part being a listing of major differences found, and the remaining half page showing information for difference ranges 2 through 5 . The next main section is the summary section for 3RCORR.DAT, with the first part listing the major differences, and the remaining half page showing the output variables in difference ranges 2 through 5 . The major difference sections for each test case only show some time steps for which large differences were actually found; the elimination of most time steps makes the overall comparison summary file easier to understand, while eliminating much redundant information. The last main section of the appendix is the general summary section, consisting of the information found in both test data files, grouped by the five difference ranges. Within each range, the output is arranged by output variable and test case file name.

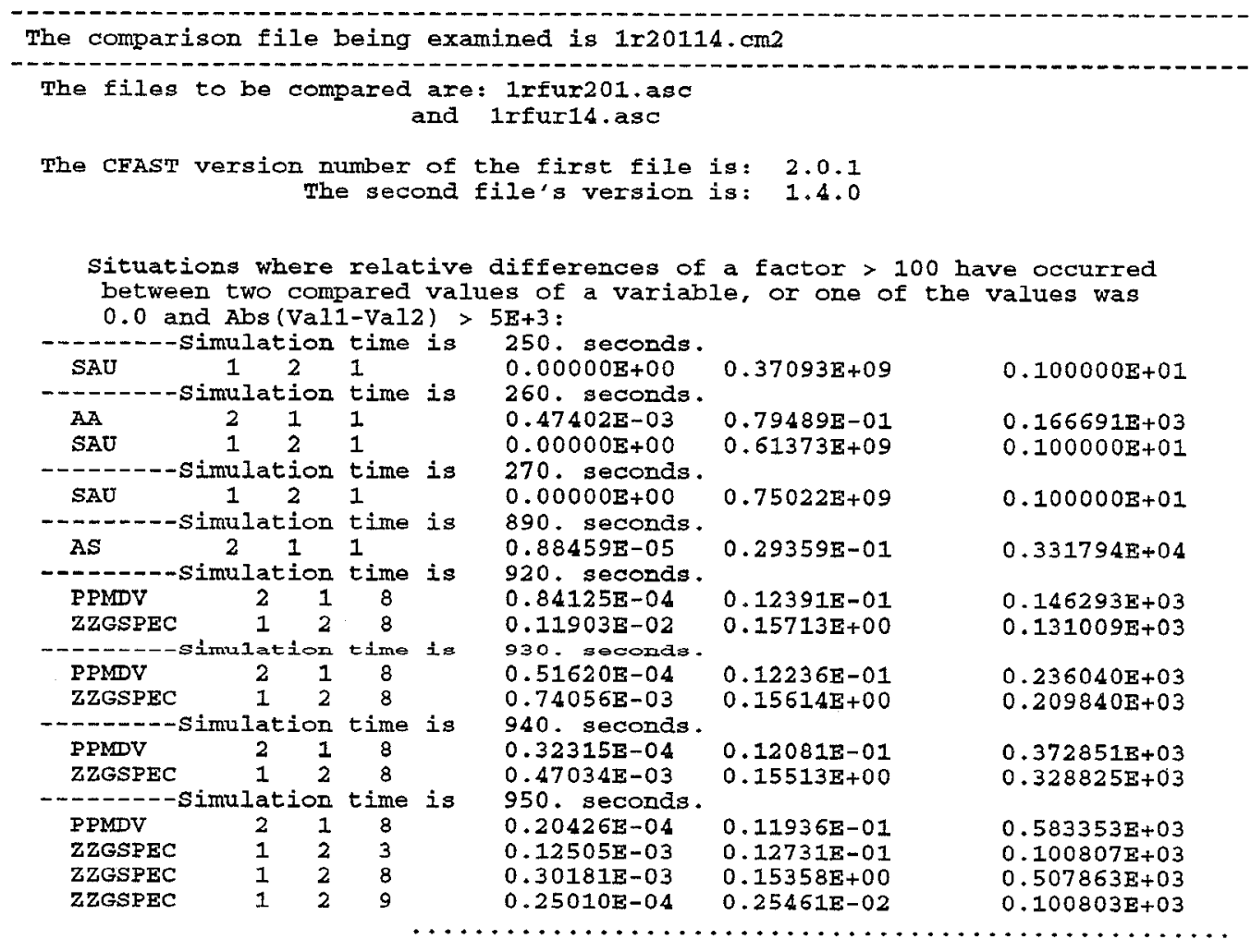




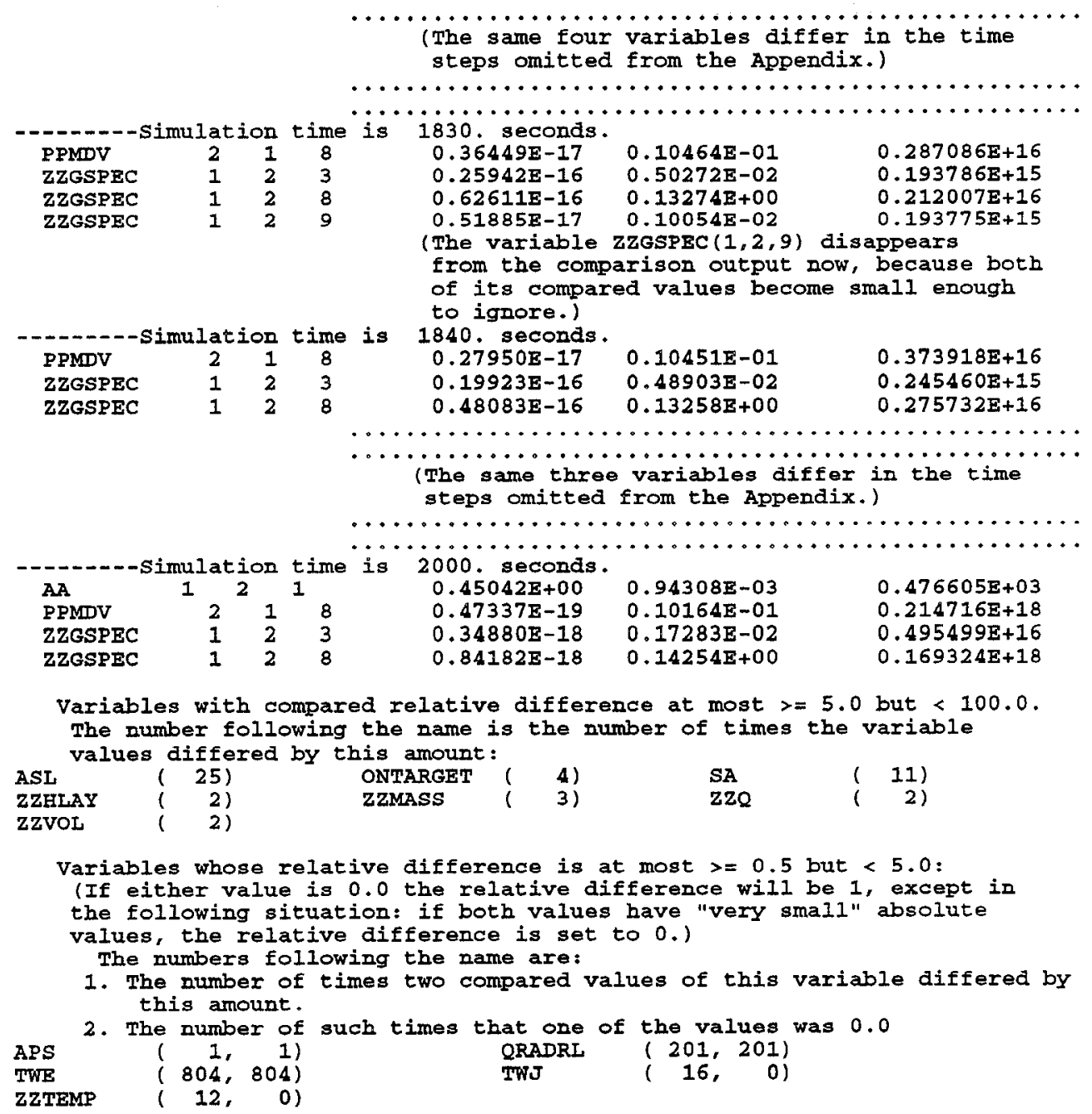

variables with compared relative difference at most $>=0.01$ but $<0.5$ :

-- NONE --

Variables with compared relative difference at most $>=0.001$ but $<0.01$ :

-- NONE --

The comparison file being examined is $3 \times 20114 . \mathrm{cm} 2$

The files to be compared are: 3rcor201.asc

and $3 r \operatorname{cor} 14$, ase

The CFAST version number of the first Eile is: 2.0 .1 The second file's version is: 1.4 .0

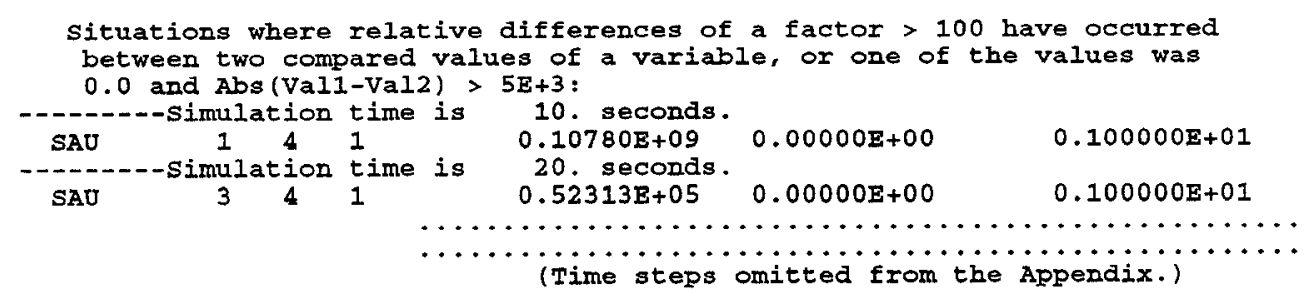




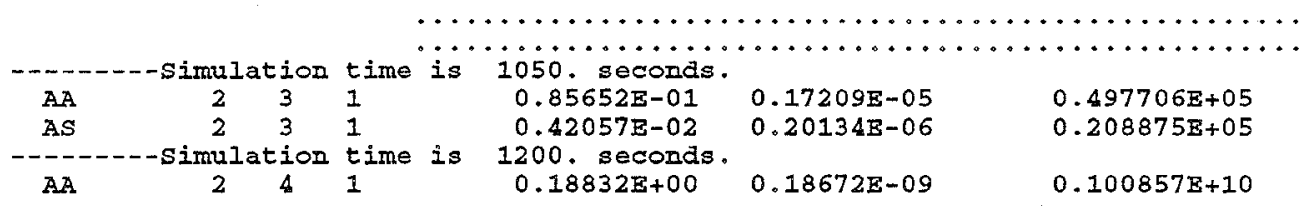

Variables with compared relative difference at most $>=5.0$ but $<100.0$.

The number following the name is the number of times the variable

values differed by this amount:

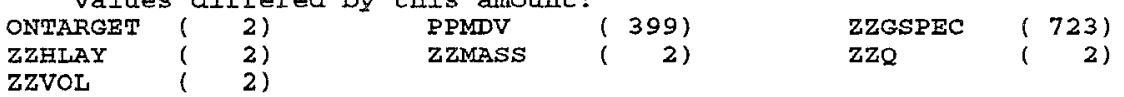

Variables whose relative difference is at most $>=0.5$ but $<5.0$ :

(If either value is 0.0 the relative difference will be 1 , except in

the following situation: if both values have "very small" absolute

values, the relative difference is set to 0. )

The numbers following the name are:

1. The number of times two compared values of this variable differed by this amount.

2. The number of such times that one of the values was 0.0

$\begin{array}{llll}\text { APS } & (1,1,1) & \text { HEATVF } & (2,2) \\ \text { QRADRL } & (121,121) & \text { TWE } & (484,484)\end{array}$

Variables with compared relative difference at most $>=0.01$ but $<0.5$ : TWJ (1128) ZZTEMP (467)

Variables with compared relative difference at most $>=0.001$ but $<0.01$ :

- NONE --

Summary of variable differences, for each data file, by range

Within each range, the output format is as follows:

CFAST variable name [\# of files this situation applies to, total number of

times this occurred, followed by the names of the comparison files in which it occurred. If all such differences in an output file had 1 of the compared values $=0$, the file is marked with an asterisk.

Final sumnary for range
Relative difference $>=100$ or one of the compared values (V1, V2)
is 0 and ABs (Vi-v2) $>5000$

$\begin{array}{lrrll}\text { AA } & {[2,} & 52] & 1 \times 20114 & 3 \times 20114 \\ \text { AS } & {[2,} & 16] & 1 \times 20114 & 3 \times 20114 \\ \text { ASL } & {[1,} & 2] & 3 r 20114 & \\ \text { PFMDV } & {[1,} & 109] & 1 \times 20114 & \\ \text { SA } & {[1,} & 2] & 3 \times 20114 & \\ \text { SAU } & {[2,} & 14] & * 1220114 & * 3 \times 20114 \\ \text { SS } & {[1,} & 1] & 3 r 20114 & \\ \text { ZZGSPEC } & {[1,} & 304] & 1520114 & \end{array}$


Final summary for range 2

Relative difference is at most $>=5.0$ but $<100.0$

\begin{tabular}{|c|c|c|c|c|}
\hline ASI & I 1 , & 25] & $\operatorname{lr2} 0114$ & \\
\hline ONTARGET & {$[2$,} & 6] & 1220114 & $3 \times 20114$ \\
\hline P PMDV & [ 1 , & 3991 & $3 \times 20114$ & \\
\hline SA & [ 1 , & 11] & $1 \times 20114$ & \\
\hline ZZGSPEC & I 1 , & $723]$ & $3 \mp 20114$ & \\
\hline ZZELAY & [ 2 , & 4] & $1 r 20114$ & $3 \times 20114$ \\
\hline ZZMASS & [ 2, & 5] & 1220114 & $3 \times 20114$ \\
\hline $\mathbf{Z Z Q}$ & 52, & 4] & $1=20114$ & 3220114 \\
\hline zzVOL & {$[2$,} & 4] $]$ & 1220114 & $3 \times 20114$ \\
\hline
\end{tabular}

Final summary for range 3

Relative difference is at most $>=0.5$ but $<5.0$

- - - - - - - -

$\begin{array}{lrrrr}\text { APS } & {[2,} & 2] & * 1220114 & * 3520114 \\ \text { HEATVF } & {[1,} & 2] & * 3 r 20114 & \\ \text { QRADRL } & {[2,} & 322] & * 1220114 & * 3220114 \\ \text { TWE } & {[2,1288]} & * 1220114 & * 3220114 \\ \text { TWJ } & {[1,} & 16] & 1220114 & \\ \text { ZZTEMP } & {[1,} & 12] & 1220114\end{array}$

Final sumnary for range 4

Relative difference is at most $>=0.01$ but $<0.5$ -

TWJ $[1,1128] \quad 3 r 20114$

ZZTEMP [ 1,467$] \quad 3520114$

Final summary for range 5

Relative difference is at most $>=0.001$ but $<0.01$

--- NONE --- 
NIST-114

(REV. 6-93)

ADMAN 4.09
U.S. DEPARTMENT OF COMMERCE

NATIONAL INSTITUTE OF STANDARDS AND TECHNOLOGY

\section{MANUSCRIPT REVIEW AND APPROVAL}

INSTRUCTIONS: ATTACH ORIGINAL OF THIS FORM TO ONE (1) COPY OF MANUSCRIPT AND SEND TO THE SECRETARY, APPROPRIATE EDITORIAL REVIEW BOARD

TITLE AND SUBTITLE (CITE IN FULL)

A CFAST Output Comparison Method and its use in Comparing Different CFAST Versions

\begin{tabular}{l|l|l|}
\hline $\begin{array}{l}\text { CONTRACT OR GRANT NUMBER } \\
\text { Internal Report }\end{array}$ & TYPE OF REPORT AND/OR PERIOD COVERED \\
\hline AUTHOR(S) (LAST NAME, FIRST INITIAL, SECOND INITIAL) & PERFORM \\
\hline
\end{tabular}

AUTHOR(S) (LAST NAME, FIRST INITIAL, SECOND INITIAL)

Alvord, D. M.

$\mathrm{X}$ NIST/GAITHERSBURG

NIST/BOULDER

JILA/BOULDER

LABORATORY AND DIVISION NAMES (FIRST NIST AUTHOR ONLY)

Building and Fire Research Laboratory, Fire Safety Engineering Division

SPONSORING ORGANIZATION NAME AND COMPLETE ADDRESS (STREET, CITY, STATE, ZIP)

\section{PROPOSED FOR NIST PUBLICATION}

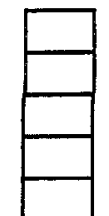

JOURNAL OF RESEARCH (NIST JRES)

J. PHYS. \& CHEM. REF. DATA (JPCRD)

HANDBOOK (NIST HB)

SPECIAL PUBLICATION (NIST SP)

TECHNICAL NOTE (NIST TN)

PROPOSED FOR NON-NIST PUBLICATION (CITE FULLY)

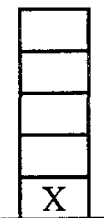

MONOGRAPH (NIST MN)

NATL. STD. REF. DATA SERIES (NIST NSRDS)

FEDERAL INF. PROCESS. STDS. (NIST FIPS)

LIST OF PUBLICATIONS (NIST LP)

NIST INTERAGENCY/NTERNAL REPORT (NISTIR)

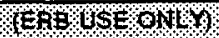

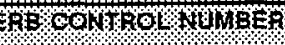

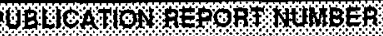

$1410 \%$

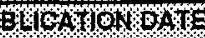

2.1615.1095

A multiple step method was developed to compare the output of CFAST simulations, produced either by the same version of CFAST, or by different versions of the model. Scenarios to be compared are run with CFAST before the method is used, producing files containing a history of the model results. The first step of the comparison method produces a text file of important output variables from each of these history files, corresponding to significant fire phenomena occurring during the course of each fire simulation. The next step of the method is used to compare two such text files, and store their differences. Finally, the last step summarizes the difference information found in one or more files from the previous step. The comparison method can be used to find differences between CFAST runs, and to track changes in the CFAST model and detect if they perform as anticipated. It has been used to compare three CFAST versions through use of a documented set of test files. This set will change as improvements are made to the model. The method can be used to find the effects whenever any substantial changes are made to CFAST, and is a useful tool for any user of the model. This report describes the comparison method in sufficient detail to serve as a user's guide, provides examples of the method's use, and discusses ways in which it could be improved and generalized.

KEY WORDS (MAXIMUM OF 9; 28 CHARACTERS AND SPACES EACH; SEPARATE WITH SEMICOLONS; ALPHABETIC ORDER; CAPITALIZE ONLY PROPER NAMES) building fires; comparison; computer models; computer programs; differences; fire models; fire research; tests

AVAILABILITY

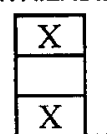

UNLIMITED

FOR OFFICIAL DISTRIBUTION - DO NOT RELEASE TO NTIS ORDER FROM SUPERINTENDENT OF DOCUMENTS, U.S. GPO, WASHINGTON, DC 20402 ORDER FROM NTIS, SPRINGFIELD, VA 22161
NOTE TO AUTHOR(S): IF YOU DO NOT WISH THIS

MANUSCRIPT ANNOUNCED BEFORE PUBLICATION, PLEASE CHECK HERE. 